Published in "Behavioural Brain Research 298, Part B: 167-180, 2016"

which should be cited to refer to this work.

\title{
Reduction in 50-kHz call-numbers and suppression of tickling-associated positive affective behaviour after lesioning of the lateral hypothalamic parvafox nucleus in rats
}

\author{
Diana M. Roccaro-Waldmeyer, Alexandre Babalian, Annelies Müller, Marco R. Celio* \\ Anatomy and Programme in Neuroscience, Faculty of Science, University of Fribourg, Rte A. Gockel 1, CH-1700 Fribourg, Switzerland
}

\section{H I G H L I G H T S}

- Wistar rats were tickled before and after excitotoxic lesioning of the lateral hypothalamic parvafox nucleus.

- Ultrasonic vocalisations (USVs) that were emitted during the tickling of rats and their tendency to approach and follow the experimenter's hand were analysed.

- Lesioning was considered successful if the number of parvalbuminimmunoreactive (PV-ir) cells in the area of the parvafox nucleus was reduced beyond a threshold level.

- Rats with bilaterally successful lesions manifested the most profound surgery-associated reduction in the number of $50-\mathrm{kHz}$ USVs and in the tendency to approach and follow the experimenter's hand.

- Positive correlations were found between each of the four investigated parameters.

\section{G R A P H I C A L A B S T R A C T}

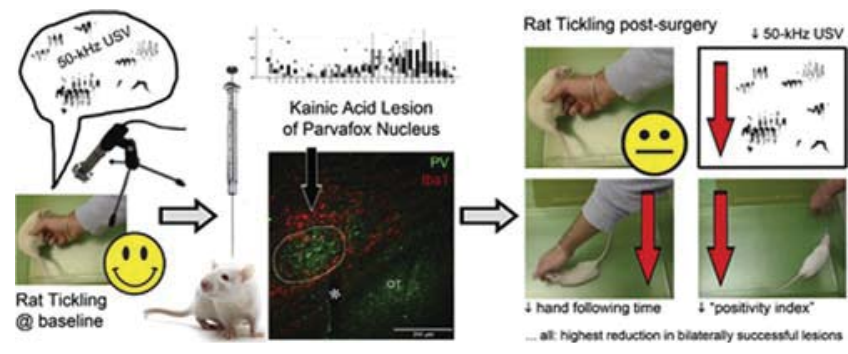

The parvafox nucleus is located ventrolaterally in the lateral hypothalamic area (LHA). Its core and shell are composed of neurons expressing the calcium-binding protein parvalbumin (PV) and the transcription factor Foxb1, respectively. Given the known functions of the LHA and that the parvafox nucleus receives afferents from the lateral orbitofrontal cortex and projects to the periaqueductal gray matter, a functional role of this entity in the expression of positive emotions has been postulated.

The purpose of the present study was to ascertain whether the deletion of neurons in the parvafox nucleus influenced the tickling-induced $50-\mathrm{kHz}$ calls, which are thought to reflect positive affective states, in rats. To this end, tickling of the animals (heterospecific play) was combined with intracerebral injections of the excitotoxin kainic acid into the parvafox nucleus.

The most pronounced surgery-associated reduction in $50-\mathrm{kHz}$ call-numbers was observed in the group of rats in which, on the basis of PV-immunoreactive-cell counts in the parvafox nucleus, bilateral lesions had been successfully produced. Two other parameters that were implemented to quantify positive affective behaviour, namely, an approach towards and a following of the hand of the tickling

\footnotetext{
* Corresponding author at: Institute of Anatomy, University of Fribourg, Rte A. Gockel 1, CH-1700 Fribourg, Switzerland.

E-mail address: marco.celio@unifr.ch (M.R. Celio).
} 
experimenter, were likewise most markedly suppressed in the group of rats with bilaterally successful lesions. Furthermore, positive correlations were found between each of the investigated parameters. Our data afford evidence that the parvafox nucleus plays a role in the production of $50-\mathrm{kHz}$ calls in rats, and, more generally, in the expression of positive emotions.

\section{Introduction}

Evidence that has accumulated over the past decades implicates the lateral hypothalamus in multifarious physiological responses, which include the modulation of not only autonomic and endocrine, but also skeletomotor and even cognitive functions (reviewed in [1]). Anatomically, it can be sub-divided into a preoptic, tuberal and posterior part along the rostrocaudal axis (reviewed in [2]). It contains two major fibre bundles - the fornix and the medial forebrain bundle (MFB) - as well as well-circumscribed cell aggregates (nuclei). The emergence of specific markers for distinct neuronal sub-populations, such as orexin/hypocretin [3], has facilitated a characterization of the functional units within the lateral hypothalamic area (LHA) and their connectivities. We have previously shown that the calcium-binding protein parvalbumin (PV) serves as a marker for yet another neuronal sub-population, which populates the core region of the parvafox nucleus (formerly "PV1-Foxb1 nucleus"). The shell surrounding the core of the nucleus is composed of small neurons, which express the transcription factor Foxb1 [4]. The nucleus is located in the tuberal part of the ventrolateral hypothalamus, between the optic tract and the fornix [5-7]. Experiments in which anterograde tracers, particularly Cre-recombinase-dependent viral ones, have been injected into PV-Cre or Foxb1-Cre mice, have revealed the parvafox nucleus to project mainly to the periaqueductal grey matter (PAG), and, more specifically, to the ventrolateral [8] and the dorsolateral [9] columns. Furthermore, in-situ hybridization has disclosed PV-expressing neurons of the parvafox nucleus to be glutamatergic and thus excitatory [10], in contrast to those in most other brain areas, such as the neocortex, the hippocampus and the cerebellum [11].

Hypotheses about possible functions of the parvafox neurons can be generated based on insights gleaned from manipulations in experimental animals, from patients in which alterations in the corresponding region of the LHA are manifested, and from imaging and stimulation studies that have investigated, in animals or humans, the LHA or the PAG, the main target of the axons emanating from the parvafox nucleus.

In humans, hamartomas arising from the lateral tuberal hypothalamus can evoke the onset of gelastic seizures, a form of epilepsy that is characterized by involuntary laughter, which may or may not be accompanied by a pleasant sensation $[12,13]$. The lateral tuberal nucleus (LTN) of primates shares topographical as well as some neurochemical features in common with the rodent parvafox nucleus $[10,14]$. Neurons of the LTN manifest pathological alterations in Pick's disease, in which loss of speech is one of the symptoms [15]. Stimulation of the hypothalamic area can induce vocalization in rats [16], cats [17] and squirrel monkeys [18]. In humans, tickling-induced, involuntary (Duchenne-type) laughter is associated with the activation of several brain regions, including the lateral hypothalamus [19]. The lateral hypothalamus has been ascribed a role in the functioning of the larynx [20] and pharynx [21], as well as in the control of vocalization [22]. Preliminary experiments in which Cre-dependent tracers were injected into the parvafox nucleus have disclosed a projection to the nucleus retroambiguus [9], which contains premotor interneurons capable to produce the motor actions required for vocalization [23]. In addition to its role in the control of vocalization, the lateral hypothalamus also harbours neuronal representations of reward value [24-26].

The ventrolateral and the dorsolateral PAG are involved in the mediation of two opposing types of emotional coping strategy (passive and active, respectively) [27-29]. The PAG is also implicated in the control of vocalization. As a relay station in the limbic vocalization-control pathway, it serves a gating function in the initiation of involuntarily produced vocalisations ([18,30]; research mainly in monkeys). Although the exact mechanisms remain elusive, the PAG appears to play a role in the production of human laughter [12,31-33]. Functional magnetic resonance imaging has revealed PAG-activity to occur in conjunction with involuntarily produced laughter [19]. Electrical [34-36] or pharmacological $[37,38]$ stimulation of the PAG induces the production of naturally sounding, species-specific vocalisations in all mammalian species that have been thus far investigated. More specifically, the caudal portion of the ventrolateral PAG has been implicated in the induction of relaxed emotional states in rats, cats and monkeys [18,27,39] .

In appetitive and neutral situations, rats emit ultrasonic vocalisations (USVs) in a high-frequency range (50-kHz USV, highfrequency calls), whereas in aversive ones, they produce USVs in a low frequency band (22-kHz USV, low-frequency calls) (reviewed in [40]). High-frequency calls are produced by juvenile or adult rats during rough-and-tumble play [41], during mating [41-44], as an expression of reward during voluntary exercise [45], as well as in response to drugs of abuse [46,47], and it is widely accepted today that they reflect a positive affective state $[46,48,49]$. Consequently, one of their functions appears to be the communication of emotional states to conspecifics [50]. The $50-\mathrm{kHz}$ calls in rats have even been compared to laughter in humans [51,52]. Rough-andtumble play in rats can be mimicked by tickling [51]. A short period of social isolation has been shown to boost the rate of ticklinginduced $50-\mathrm{kHz}$ USVs $[51,53]$ by enhancing the social motivation of the animals. Rats emitting high numbers of tickling-induced 50$\mathrm{kHz}$ USVs have been shown to approach the hand of the tickling experimenter with a short latency period [54]. In addition to conveying information appertaining to affective states, $50-\mathrm{kHz}$ USVs are suggested to fulfil important communicative functions and to be involved in the establishment and maintenance of close social contacts [44,55-58]. Rats use low- frequency (22-kHz) alarm calls as a warning to conspecifics of imminent dangers, with a view to promoting a survival-enhancing behavioural strategy in the colony as a whole [59-61]. 22-kHz USVs can be elicited by pharmacological stimulation of the lateral PAG [62], but also by electrical stimulation of the dorsal (dorsomedial + dorsolateral) and even ventrolateral PAG [63].

The purpose of the present study was to ascertain whether neurons of the parvafox nucleus play a role in the expression of positive emotions in rats, as evidenced by the production of $50-\mathrm{kHz}$ USVs. To this end, the tickling-induced vocalisations that were emitted by adolescent Wistar rats, as well as the tendency to seek (approach and follow) the experimenter's hand, were analysed before and 
after lesioning of the LHA in the region of the parvafox nucleus by targeted injections of the excitotoxin kainic acid.

\section{Materials and methods}

\subsection{Animals}

The experiments were performed on three cohorts of animals. In each cohort, Wistar-rat pups of a common litter and of both sexes were weaned after three weeks of age ( $n=10$ in cohort one, $n=11$ in cohort two, $n=16$ in cohort three). They were housed individually in cages $(42.5 \times 21 \times 20 \mathrm{~cm})$ containing bedding and a cardboard tube, for up to four weeks. The rats had ad libitum access to water and to rodent chow, and were maintained on a 12-h-light/12-hdark cycle. All procedures were conducted in strict accordance with the Swiss laws on animal experimentation and were approved by the Veterinary Commission for Animal Research of the Canton of Fribourg.

\subsection{Tickling experiment}

In all three cohorts, rats underwent a tickling session on Mondays, Tuesdays and Wednesdays during a four-week period (12 sessions in all). After a baseline period spanning the first two weeks of tickling, surgery was performed. The experimental design is summarized in Fig. 1. Each tickling session (duration $=5$ min per rat) was comprised of ten 30-s manipulations (positions), which included handling and break-periods. The manipulations followed the protocol that was elaborated by Schwarting et al. [64] and were performed in a cage $(54.5 \times 37 \times 20 \mathrm{~cm})$ without bedding. The very first tickling session per cohort involved four break-periods at positions $1,3,5$ and 8 . In the 11 subsequent tickling sessions, the number of break-periods was reduced to two, at positions 2 and 5 . Furthermore, the very first tickling session per cohort included two standardised handling procedures (stroking the rat from head to tail at position 2, and passing it from one hand to the other at position 4), which were reduced to one (passing the rat from one hand to the other at position 1 ) in the 11 subsequent tickling sessions. In the remaining positions, the tickling manipulations that were referred to as "push \& drill" (x2), "grab \& tickle" (x2), "handchase" (x1), "neck tickle" (x1) and "belly tickle" (x1) in the original publication [64] were performed. In the very first tickling session per cohort, only the first four of the manipulations were performed once. In each cohort, all tickling sessions were executed by the same experimenter, who was blind to the treatment allocations and who was not involved in any stage of the experimental analysis. Only rats that emitted sufficient numbers of $50-\mathrm{kHz}$ USV at baseline (in general: $\geq 100$ USVs in total during the $10 \times 30$ s of tickling manipulations) were used for surgery and for the post-surgical tickling sessions (cohort 1: $n=5$, cohort 2: $n=7$, cohort 3: $n=5$ ).

\subsection{Surgery and lesioning}

Rats were anaesthetised by injecting a salinic $(0.9 \%)$ mixture of ketamine $(60 \mathrm{mg} / \mathrm{kg}$ of body weight) and xylazine $(15 \mathrm{mg} / \mathrm{kg}$ of body weight) into the peritoneal cavity. The head of the animal was secured in a stereotaxic apparatus (Kopff) and craniotomy was performed over the targeted region in the lateral hypothalamus on both sides. Excitotoxic lesioning of the parvafox nucleus was induced by a local injection of kainic acid [Sigma (1\% in saline)]. The acid was injected into the test animals (cohort $1: n=3$, cohort 2: $n=5$, cohort 3: $n=4$ ) via a fine-bored needle (external diameter: $0.14 \mathrm{~mm}$; Ga: 34 ) which was connected to a $2.5-\mu l$ Hamilton syringe that was mounted on a manual microinjection unit (Kopff, modell 5000). Two injections, separated by a rostro-caudal distance of $0.7 \mathrm{~mm}$, were delivered on each side ( 4 in all) at the following stereotaxic coordinates (in $\mathrm{mm}$, with respect to Bregma and to the brain surface): antero-posterior (AP): -2.3 and -3 ; medio-lateral (ML): \pm 2.2 ; dorso-ventral (DV): -9 . At each site, $55-75 \mathrm{nl}$ of the excitotoxin were injected over a period of $1 \mathrm{~min}$. After the injection, the needle was left in place for 3-5 min to allow for drug diffusion. The needle was then withdrawn, the skin over the skull was sutured, and the animals were left to recover. In the control animals, we either injected a solution of physiological saline $(0.9 \%)$ instead of the kainic acid, using the above-described protocol (saline controls; cohort 1: $n=1$, cohort $2: n=1$ ), or merely cut and sutured the skin over the skull (suture controls; cohort 1: $n=1$, cohort 2: $n=1$, cohort 3: $n=1$ ). The mean body weight of the rats on the day of surgery was $141.3 \mathrm{~g}$ in cohort $1,137.6 \mathrm{~g}$ in cohort 2 and $188.6 \mathrm{~g}$ in cohort 3.

\subsection{Recording and analysis of ultrasonic vocalisations (USVs)}

During all tickling sessions, ultrasonic vocalisations (USVs) were detected by an ultrasonic condenser microphone (CM16/CMPA, Avisoft Bioacoustics, Berlin, Germany), which was located roughly 22 centimetres above the cage floor and laterally extended into the cage by about 3 centimetres. The acoustic signals were amplified and then digitized at $300 \mathrm{kHz}$ with 16-bit resolution (UltraSoundGate $116 \mathrm{H}$, Avisoft Bioacoustics) and were displayed on a computer screen in real-time using Recorder_USGH software (Avisoft Bioacoustics). USVs were analysed off-line using SASLab Pro 5.1 software (Avisoft Bioacoustics). Spectrograms were produced using the following parameters: FFT-length $=512$, frame-size $=75 \%$, window: hamming, overlap $=50 \%$. A cut-off frequency of $18 \mathrm{kHz}$ was set to eliminate insignificant low-frequency noise, and individual USVelements were manually selected. The total number of USVs that were emitted during the 5 min of tickling was determined as well as duration and peak frequency of individual calls, which served as a basis for the classification into the three different categories that have been described by Schwarting et al. [64]: high-frequency calls (peak frequency $>33 \mathrm{kHz}$ : "50-kHz calls"), long low- frequency calls (peak frequency $<33 \mathrm{kHz}$, USV-duration $>300 \mathrm{~ms}$ : " $22-\mathrm{kHz}$

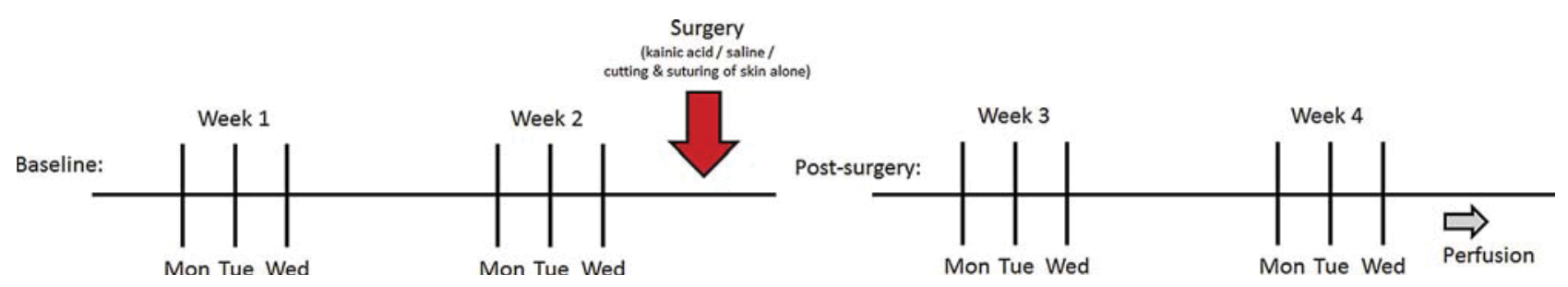

Fig. 1. Schematic representation of the experimental design.

Rats were tickled on Mondays, Tuesdays and Wednesdays for a period of four weeks. At the end of the second week, surgery was performed (test animals: stereotactic injection of kainic acid into the parvafox nucleus region; control animals: analogous injection of saline or mere cutting and suturing of the skin). Each of the vertical lines represents a 5-min period of tickling and a performance of the "hand-approach latency" (HAL) test. 
calls") and short low-frequency calls (peak frequency $<33 \mathrm{kHz}$, USVduration $<300 \mathrm{~ms}$ ).

\subsection{Recording and analysis of behaviour}

A regular video camera, placed above the cage, was used to record the behaviour of each rat during the tickling sessions and during the "hand- approach latency" (HAL) test which was always conducted immediately afterwards [53].

In the HAL-test, the rat was placed in one corner of the same cage that was used for tickling, facing the back of the experimenter's hand, which was placed in the corner diagonal to the rat, and the latency to approach the hand was recorded. Whenever a rat touched the hand with its head or whiskers, it received $10 \mathrm{~s}$ of "grab \& tickle" stimulation before being put back into the same corner. It was permitted to approach the experimenter's hand again for up to a total of five times. If a rat did not touch the experimenter's hand within $30 \mathrm{~s}$, the HAL-test was terminated and the rat was put back into its home cage. The following two parameters were quantified in an off-line analysis of the HAL test videos: the total number of hand approaches (0-5), and, for each successful approach, the latency to touch the experimenter's hand (0-30 s). These two parameters were combined to yield an "HAL-positivity index", which was derived by dividing the total number of hand approaches by the mean latency to touch the experimenter's hand.

An off-line analysis of the video-taped tickling sessions was conducted to determine the total time during which individual rats actively followed the experimenter's hand during the "hand-chase" manipulation. Observer XT 11 software was used to estimate the total following time.

\subsection{Immunohistochemistry}

Rats were perfused at the end of the fourth week with physiological saline, followed by a $4 \%$ paraformaldehyde solution. Details of the procedure are described elsewhere [6]. 80- $\mu \mathrm{m}$-thick coronal cryosections through the brain specimens were collected in $0.1 \mathrm{M}$ phosphate buffer ( $\mathrm{pH}$ 7.3). All sections along the rostrocaudal aspect of the parvafox nucleus (in general 28 [range: 25-30] sections, spanning a total length of 2.24 [range: $2.0-2.4$ ] $\mathrm{mm}$ ) were incubated first with a monoclonal primary antibody against PV (PV235, 1:1000, Swant, Marly, Switzerland) for $24-48 \mathrm{~h}$ at $4{ }^{\circ} \mathrm{C}$, then with biotinylated anti-mouse IgG (1:200, Vector Laboratories, Burlingame, CA) for $2 \mathrm{~h}$ at ambient temperature, and finally with streptavidin-Alexa488 (1:200, Jackson Immunoresearch Laboratory, West Grove, PA) for $3 \mathrm{~h}$ at ambient temperature. In addition, every fourth section of the specimens from rats in cohort two was exposed first to rabbit anti-Iba1 (ionized calcium-binding adaptor molecule 1; Wako Pure Chemicals, Osaka, Japan $[0.25 \mu \mathrm{g} / \mathrm{ml}]$ ) for $24 \mathrm{~h}$ at $4{ }^{\circ} \mathrm{C}$ and then to Cy3-conjugated donkey anti-rabbit antibody (Jackson Immunoresearch Laboratory [1:200]) for $2 \mathrm{~h}$ at ambient temperature.

\subsection{Image analysis}

In each section along the rostrocaudal aspect of the parvafox nucleus, PV-immunoreactive cells located in the nucleus region were counted in a LEICA DM6000 epifluorescence microscope connected to a C4742-95-12NR camera (Hamamatsu Photonics, Hamamatsu, Japan), using a $\times 20$-objective.

\subsection{Statistical analysis}

IBM SPSS Statistics 21.0 was used for all statistical analyses and to create graphs.
One-way, repeated-measures ANOVA was used to investigate baseline changes in the three parameters of interest (highfrequency vocalisations, HAL-positivity index, following time) on a group basis. Since Mauchly's test of sphericity was not statistically significant, sphericity was assumed.

Box-plots display data appertaining to each group, whereas regression analyses compare the data of individual animals.

For regression analyses, the following regression models were applied: linear, logarithmic, power, logistic, exponential. The model with the lowest $p$-value was selected for demonstration.

Statistical significance was set at $p<0.05$.

\section{Results}

\subsection{Evaluation of lesions}

\subsubsection{Semi-quantitative analysis of}

parvalbumin-immunoreactive (PV-ir) cells in the parvafox nucleus region

Control animals in the three cohorts $(n=5)$ did not have comparable numbers of PV-ir cells (cohort 1: $164 \pm 23$ cells per side [mean $\pm \mathrm{SD}$ ]; cohort 2: $110 \pm 18$; cohort 3: $321 \pm 26)$. Hence, in the lesioned test animals, the total number of PV-ir cells per side was expressed as a percentage of the mean total number on the same side in the (1-2) control animal(s) of the same cohort (Table 1). Since the longitudinally extending PV core of the parvafox nucleus spans a width of no more than about $0.5 \mathrm{~mm}$ in the dorsoventral and the mediolateral planes, difficulty was experienced in hitting it precisely with the stereotactic injection needle. Consequently, the percentages of the total numbers of PV-ir cells in the kainic acid injected test animals varied widely, namely between $7 \%$ and $155 \%$. Test animals with a percentage of $<60 \%$ on both sides were classified as having bilaterally successful lesions $(n=5)$; those with a percentage of $<60 \%$ on one side, but $>60 \%$ on the other were classified as having unilaterally successful lesions $(n=4)$; and those with a percentage of $>60 \%$ on both sides as having control-like lesions $(n=3)$. Cell- counting data appertaining to individual sections through the parvafox nucleus of rats in each of the four groups are depicted in Fig. 2; those appertaining to each of the 17 individual rats, as well as positions of the injection needles, are presented in Supplementary Fig. 1.

\subsection{Staining for microglia}

Immunostaining with antibodies against Iba1 was performed to visualise the microglia on sections through the brains of the seven animals in cohort two. Iba1 is a calcium-binding protein specifically expressed in microglia [65], which are activated in regions where cell death and inflammation occur (see, for example, [66]). Microglia were considered to be activated if they were present at high density and if they manifested an enlarged soma with relatively few cytoplasmic processes. No activated microglia were observed in the brain of the suture-control rat (Fig. 3A). In the saline-control rat, activated microglia were encountered along some of the four needle-tracks (not shown). In rats classified as having control-like lesions, activated microglia were likewise detected along needle-tracks or in accumulations close by, but these accumulations were usually located either dorsally or laterally relative to the parvafox nucleus. The sole exception was rat 381_12, in which some activated microglia were detected within the core of the nucleus, amongst a normal number of PV-ir cells, as well as within the surrounding shell of Foxb1-expressing cells, which could not be visualised in the present study. Most importantly, in both rats classified as having unilaterally successful lesions, dense accu- 
Table 1

Quantification of PV-ir cell numbers and consequent group assignment of the 17 rats used in the study.

\begin{tabular}{|c|c|c|c|c|c|c|}
\hline Cohort & Rat & \multicolumn{2}{|c|}{$\begin{array}{l}\text { Absolute numbers of PV-ir cells } \\
\text { counted }\end{array}$} & \multicolumn{3}{|c|}{$\begin{array}{l}\text { Numbers of PV-ir cells counted, expressed } \\
\text { as a percentage of the respective } \\
\text { cohort-control values }\end{array}$} \\
\hline 1 & $141 / 12$ & 189 & 181 & $112 \%$ & $113 \%$ & Suture-control \\
\hline 1 & $142 / 12$ & 157 & 130 & $88 \%$ & $87 \%$ & Saline-control \\
\hline 1 & $140 / 12$ & 32 & 43 & $19 \%$ & $35 \%$ & Bilaterally successful lesion \\
\hline 1 & $143 / 12$ & 63 & 65 & $40 \%$ & $53 \%$ & Bilaterally successful lesion \\
\hline 1 & $144 / 12$ & 42 & 42 & $22 \%$ & $28 \%$ & Bilaterally successful lesion \\
\hline 2 & $382 / 12$ & 97 & 140 & $90 \%$ & $109 \%$ & Suture-control \\
\hline 2 & $379 / 12$ & 96 & 105 & $110 \%$ & $91 \%$ & Saline-control \\
\hline 2 & $381 / 12$ & 119 & 102 & $124 \%$ & $101 \%$ & Control-like lesion \\
\hline 2 & $384 / 12$ & 108 & 120 & $117 \%$ & $121 \%$ & Control-like lesion \\
\hline 2 & $385 / 12$ & 149 & 170 & $155 \%$ & $136 \%$ & Control-like lesion \\
\hline 2 & $380 / 12$ & 80 & 34 & $106 \%$ & $44 \%$ & Unilaterally successful lesion \\
\hline 2 & $383 / 12$ & 53 & 124 & $55 \%$ & $124 \%$ & Unilaterally successful lesion \\
\hline 3 & $68 / 15$ & 347 & 295 & $100 \%$ & $100 \%$ & Suture-control \\
\hline 3 & $69 / 15$ & 185 & 314 & $53 \%$ & $106 \%$ & Unilaterally successful lesion \\
\hline 3 & $73 / 15$ & 57 & 206 & $16 \%$ & $70 \%$ & Unilaterally successful lesion \\
\hline 3 & $71 / 15$ & 127 & 20 & $37 \%$ & $7 \%$ & Bilaterally successful lesion \\
\hline 3 & $74 / 15$ & 64 & 120 & $18 \%$ & $41 \%$ & Bilaterally successful lesion \\
\hline
\end{tabular}

Absolute and relative numbers of PV-ir cells counted on both sides in individual rats. The relative numbers represent percentages of control-rat values. Since the control animals in the different cohorts did not have comparable numbers of PV-ir cells, lesioning efficiency was always assessed by comparing cell numbers for animals in the same cohort only. $60 \%$ was defined as the threshold value for a successfully lesioned side.
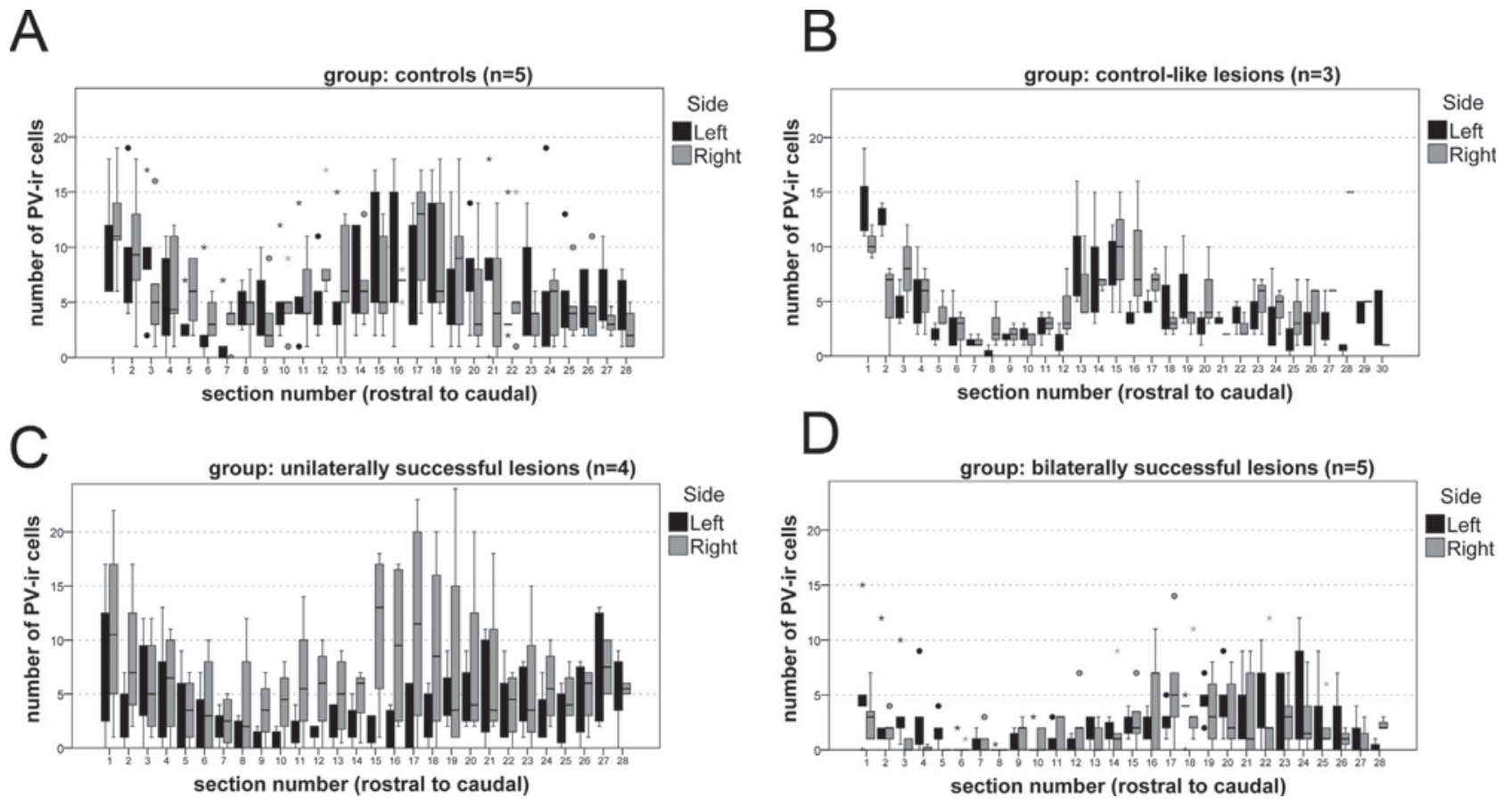

Fig. 2. Classification of rats into four groups according to the number of parvalbumin-immunoreactive (PV-ir) neurons that survived excitotoxic lesioning of the parvafox nucleus region with kainic acid.

Numbers of PV-ir cells counted on individual sections through the parvafox nucleus in the four groups of rats. (A): controls $(n=5)$; (B): control-like lesions ( $n=3)$; (C): unilaterally successful lesions $(n=4)$; and (D): bilaterally successful lesions $(n=5)$. Data appertaining to the left and the right parvafox nucleus are depicted in black and grey, respectively. In these and in all subsequent box-plots, outliers (values at a distance of 1.5-3.0 box-lengths from the box) are indicated with circles and extreme values (at a distance of $>3$ box-lengths from the box) with asterisks. Note the typical distribution of the PV-ir cells along the rostrocaudal axis in the control rats (A), and the clear reduction in cell numbers at most of the rostrocaudal levels in the animals with bilaterally successful lesions (D).

mulations of activated microglia, centred around the PV-ir cells or their dendritic remnants, were revealed in several of the sections through the successfully lesioned side (Fig. 3B).

\subsection{Evaluation of ultrasonic vocalisations (USVs)}

The absolute numbers of USVs in the three categories (highfrequency or $50-\mathrm{kHz}$ calls/short low-frequency calls/long low- frequency or $22-\mathrm{kHz}$ calls), that were emitted by rats in the four groups during the 12 tickling sessions are represented in Fig. 4.

The number of high-frequency calls increased significantly during the six baseline days in the group of all 17 rats used in this study (ANOVA, $F=19.23, p<0.001$ ). When the four rat groups were analysed separately, the finding was the same in each group except that in which control-like lesions had been produced. In this latter group, the parameter had plateaued by about tickling day 4 . With 

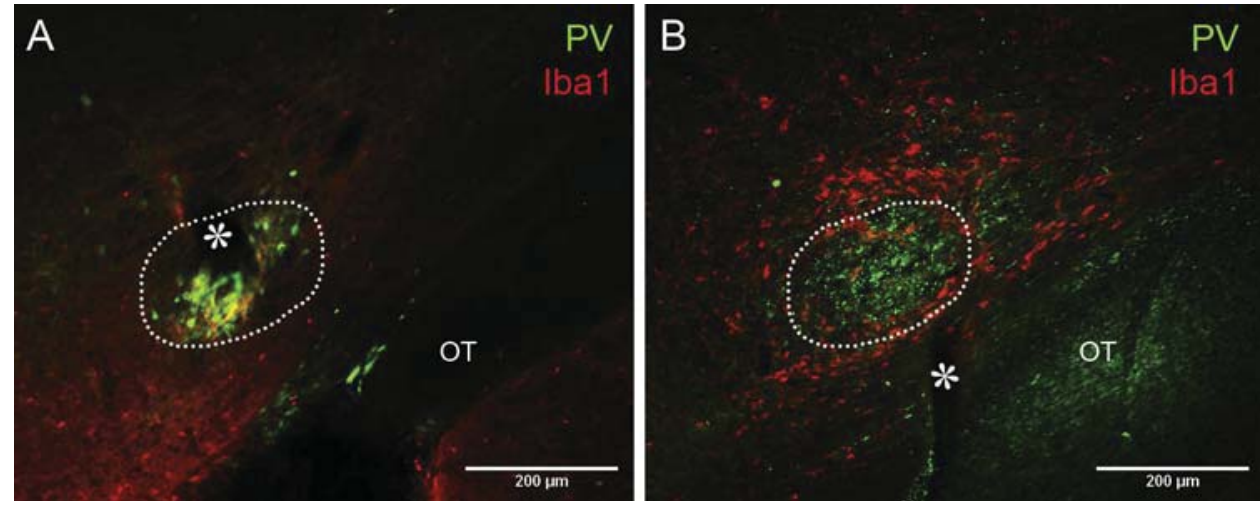

Fig. 3. Activated microglia appear in regions where neuronal death is evident.

Fluorescence photomicrographs of two exemplary sections after immunostaining for PV (green) and for a microglial marker (Iba1, red) in a suture-control rat (A) and in a rat with a unilaterally successful lesion (B). Activated microglia are absent from the brain of the suture-control rat (A), as evidenced by the relatively low numerical density of the cells, their small somal size and their abundant cytoplasmic processes. Microglia were encountered along needle-tracks, even after an injection of saline. After an injection of kainic acid, they were observed close to the tip of the needle. Dense accumulations of microglia, with morphological features suggestive of an activated state (enlarged somal size and relatively few cytoplasmic processes), were detected in the area of the parvafox nucleus (encircled with a broken line) only in conjunction with successful lesioning (B). White asterisks point to arterioles, which are typically observed in the parvafox nucleus region. OT =optic tract.

A

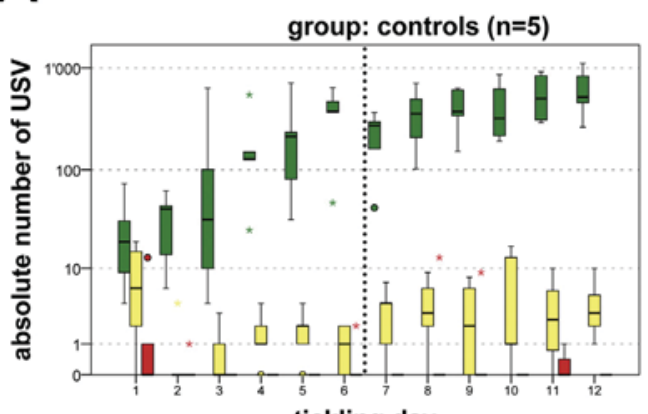

tickling day

C

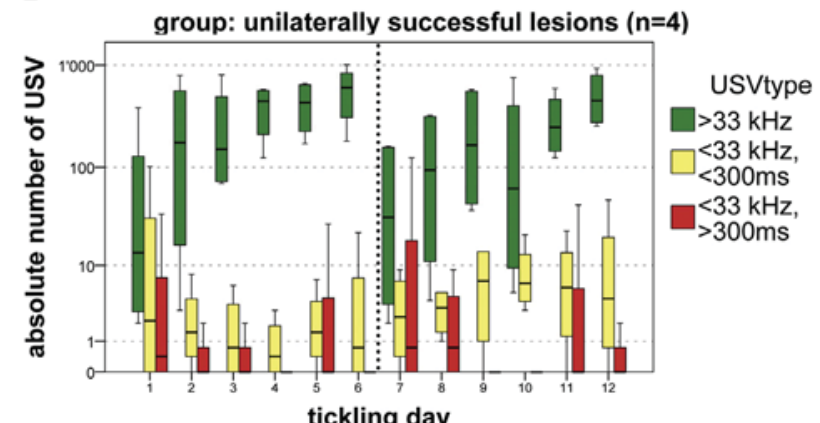

$\mathrm{B}$

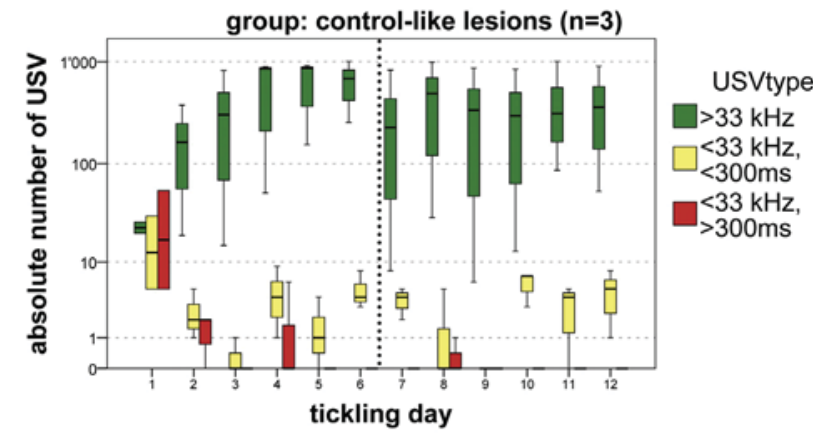

D

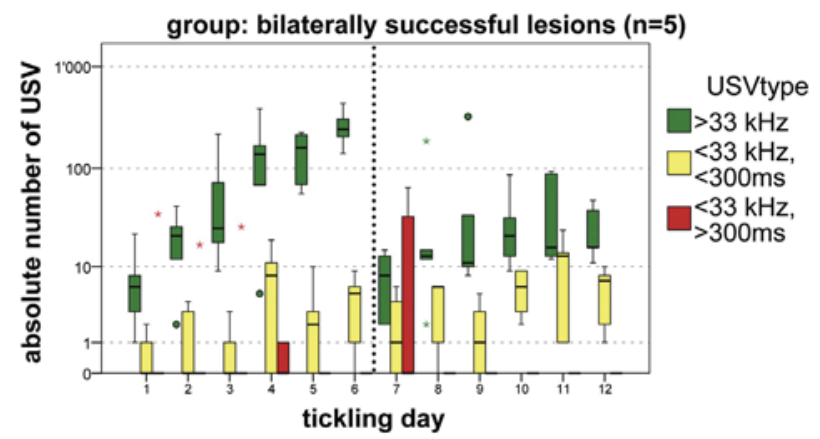

Fig. 4. Numbers of high-frequency USVs (" $50-\mathrm{kHz}$ calls”, $>33 \mathrm{kHz}$ ) are greatly reduced after bilaterally successful lesioning of the parvafox nucleus (PV sub-population). Absolute numbers of ultrasonic vocalisations (USV) in the three categories that were emitted by the four groups of rats during individual tickling sessions. Green boxes correspond to high-frequency calls (" $50-\mathrm{kHz}$ calls": peak frequency $>33 \mathrm{kHz}$ ), yellow boxes to short low-frequency calls (peak frequency $<33 \mathrm{kHz}$, duration $<300 \mathrm{~ms}$ ), and red boxes to long low-frequency calls (" $22-\mathrm{kHz}$ calls": peak frequency $<33 \mathrm{kHz}$, duration $>300 \mathrm{~ms}$ ). In this figure and in subsequent ones, broken vertical lines separate baseline from post-surgical tickling sessions. In control rats, the number of 50-kHz calls emitted after surgery was comparable to or even higher than that on baseline day 6 (A), whereas in rats with bilaterally successful lesions, it was greatly reduced (D). After surgery, 22-kHz calls were produced predominantly by rats with uni- (C) or bilaterally (D) successful lesions. Note that the ordinate scales are logarithmic.

the exception of one single animal (control 141_12), each of the rats produced more high-frequency calls at later than at earlier baseline days.

For each rat, the number of high-frequency calls emitted during each tickling session was expressed as a percentage of the number of high-frequency calls emitted during the last baseline session (tickling day 6 , set to $100 \%$ ). Fig. 5 depicts relative numbers of high-frequency calls emitted by rats that were classified together into one of the four groups. In Supplementary Fig. 2 (right parts: S2A2-S2R2) the same data are presented for each rat individually. In all four groups, the number of high-frequency calls decreased between the last baseline day (tickling day 6) and the first postsurgical day (tickling day 7) in at least one animal. However, in control animals (Fig. 5A) and in animals with control-like lesions (Fig. 5B), the number of high- frequency calls had returned to or had overshot baseline levels by tickling day 8 . The sole exception 
A

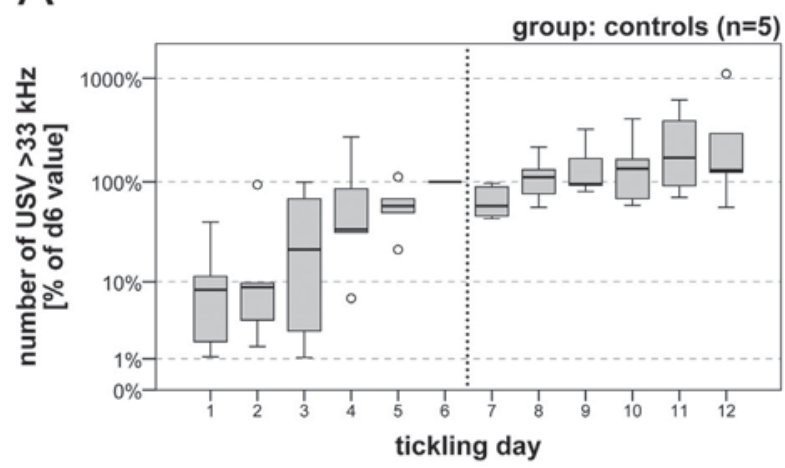

C

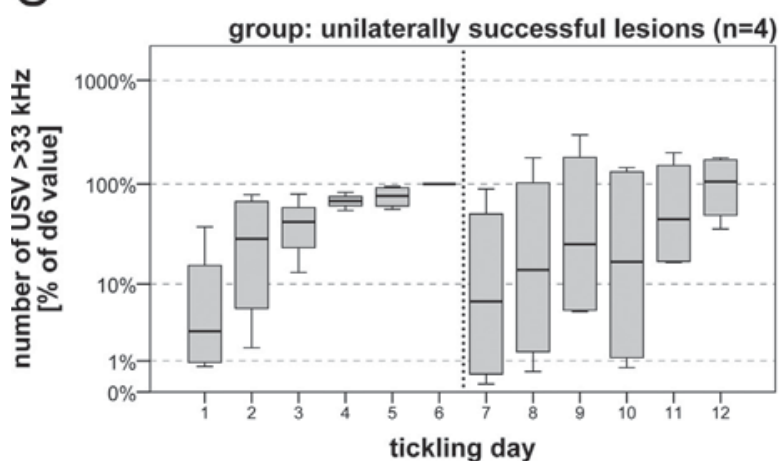

B

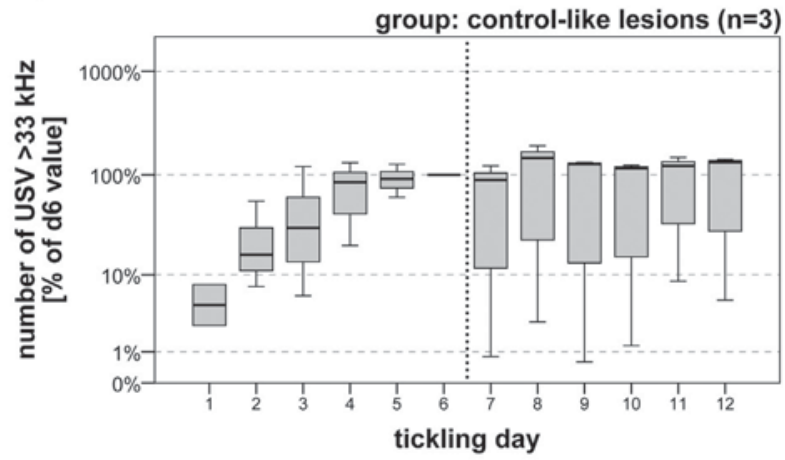

$\mathrm{D}$

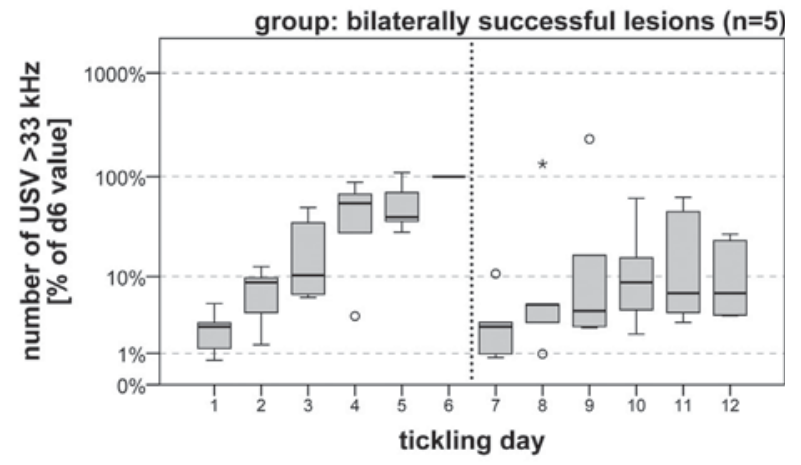

Fig. 5. Numbers of high-frequency calls are reduced more profoundly and more persistently after bilaterally than after unilaterally successful lesioning of the parvafox nucleus (PV sub-population).

Relative numbers of high-frequency calls (" $50-\mathrm{kHz}$ calls": peak frequency $>33 \mathrm{kHz}$ ) emitted by the four groups of rats during individual tickling sessions, expressed as a percentage of the number of high-frequency calls emitted by each rat during the last baseline session (day 6 , set to $100 \%$ ). In the control group, the mean relative number of $50-\mathrm{kHz}$ calls that were emitted post- surgically varied between $67 \%$ (day 7) and $341 \%$ (day 12) of the day-6 baseline values (A), whereas in rats with bilaterally successful lesions, it was reduced to between $4 \%$ (day 7 ) and $51 \%$ (day 9 , note the extreme outlier) of the day- 6 baseline values (D). Note that the ordinate scales are logarithmic.

was rat 381_12, in which the number of high-frequency calls was markedly reduced during the six post-surgical sessions throughout (Fig. S2F). Most importantly, in the group of animals with bilaterally successful lesions, the number of high-frequency calls was greatly reduced after lesioning, at least during the first four tickling sessions (Fig. 5D), with only one exception (74_15, see Fig. S2R). In rats with unilaterally successful lesions (Fig. 5C), the situation resembled that in either the control animals (69_15, Fig. S2L and 73_15, Fig. S2M) or in the rats with bilaterally successful lesions (380_12, Fig. S2I and 383_12, Fig. S2K).

The number of vocalisations in each of the three USV categories that were produced by individual rats during the 12 tickling sessions are shown in Supplementary Fig. 2 (left parts: S2A1-S2R1). Long low-frequency calls were emitted mainly during the first baseline week. During the last two baseline tickling sessions, they were produced by only two rats (141_12, Fig. S2A1 and 380_12, Fig. S2I1). After surgery, long low- frequency calls were emitted mainly by several of the rats classified as having uni- or bilaterally successful lesions (Fig. S2I1-S2R1), but also by one in the saline-control group (379_12, Fig. S2D1).

Of all the USVs that were emitted by rats during the first four tickling sessions after the production of bilaterally successful lesions, $9.9 \%$ were long low-frequency calls and only $83.1 \%$ highfrequency ones (Table 2). In the group of rats with unilaterally successful lesions, $4.0 \%$ of the USVs were long low-frequency calls and 93.2\% high-frequency ones. In the other two groups of animals, at least $98.6 \%$ of all USVs emitted post-surgically by the tickled rats were high-frequency calls; no more than $0.3 \%$ of the USVs were long low- frequency ones.
We conclude from these data that successful lesioning of PVir neurons in the parvafox nucleus is accompanied by a reduction in the number of $50-\mathrm{kHz}$ calls and, in some cases, by an increase in the number of $22-\mathrm{kHz}$ ones. Furthermore, unilaterally successful lesioning on either the left or the right side likewise had the capacity to elicit a reduction in the number of $50-\mathrm{kHz}$ calls.

\subsection{Evaluation of behavioural data}

The inter-individual performances in the "hand-approach latency (HAL) test" (HAL-positivity index) varied greatly, even under the same conditions (e.g. between the suture-controls at baseline). Furthermore, also the intra-individual HAL-performance of several of the rats between the experimental days was subjected to a considerable variation.

The HAL-positivity index increased significantly during the six baseline days in the group of all 17 rats used in the present study (ANOVA, $F=5.42, p<0.001$ ). However, when the four rat groups were analysed separately, this finding held true only for the group of animals with control-like lesions. Moreover, a few animals attained higher values during the first than during the second baseline week. For these reasons, all six baseline values for the HAL-positivity index were compared to all six post-surgical ones.

The mean HAL-positivity index for each of the four rat groups during the baseline days varied between 0.159 and 1.112 (Table 2). In each of the four groups, the mean HAL-positivity index was higher at baseline than after surgery. The value decreased to $78 \%$ of the baseline mean in the control group ( 0.253 vs. 0.197$)$, to $68 \%$ in animals with control-like lesions (1.112 vs. 0.751 ), to $71 \%$ in 
Table 2

Group-wise comparison of numbers of emitted vocalisations per call-type, of HAL-positivity index, and of hand-following time before and after surgery.

\begin{tabular}{|c|c|c|c|c|c|c|c|}
\hline Group-condition & $\begin{array}{l}\text { High- } \\
\text { frequency } \\
\text { calls: mean } \\
\text { (row sum\%) }\end{array}$ & $\begin{array}{l}\text { Short } \\
\text { low-frequency } \\
\text { calls: mean } \\
\text { (row sum\%) }\end{array}$ & $\begin{array}{l}\text { Long } \\
\text { low-frequency } \\
\text { calls: mean } \\
\text { (row sum\%) }\end{array}$ & $\begin{array}{l}{[/ s]:} \\
\text { Mean } \pm S D\end{array}$ & $\begin{array}{l}\text { HAL-positivity } \\
\text { index }\end{array}$ & $\begin{array}{l}\text { Hand- } \\
\text { following } \\
\text { time } \\
{[\% \text { of day- } 6 \text { value]: }} \\
\text { Mean } \pm \text { SD }\end{array}$ & $\begin{array}{l}\text { Hand- } \\
\text { following } \\
\text { time } \\
\text { [\% of day- } 6 \text { value] } \\
\text { Range }\end{array}$ \\
\hline Controls-baseline & $277(99.4 \%)$ & $1(0.5 \%)$ & $0(0.0 \%)$ & $0.253 \pm 0.203$ & $0.062-0.630$ & $88.6 \pm 29.5$ & $42.2-121.5$ \\
\hline Controls-postsurgery & $367(98.6 \%)$ & $4(1.1 \%)$ & $1(0.3 \%)$ & $0.197 \pm 0.087$ & $0.108-0.338$ & $67.7 \pm 34.3$ & $23.7-125.0$ \\
\hline Control-like lesions-baseline & $631(99.3 \%)$ & $4(0.6 \%)$ & $1(0.1 \%)$ & $1.112 \pm 0.422$ & $0.650-1.671$ & $125.9 \pm 19.1$ & $99.2-143.0$ \\
\hline Control-like lesions-postsurgery & $411(99.3 \%)$ & $3(0.7 \%)$ & $0(0.0 \%)$ & $0.751 \pm 0.603$ & $0.049-1.522$ & $62.9 \pm 29.8$ & $29.0-101.5$ \\
\hline Unilaterally successful lesions-baseline & $481(98.9 \%)$ & $3(0.7 \%)$ & $2(0.5 \%)$ & $0.484 \pm 0.264$ & $0.211-0.814$ & $86.7 \pm 20.0$ & $62.8-111.8$ \\
\hline Unilaterally successful lesions-postsurgery & $198(93.2 \%)$ & $6(2.8 \%)$ & $9(4.0 \%)$ & $0.344 \pm 0.181$ & $0.167-0.595$ & $49.9 \pm 14.8$ & $29.4-68.2$ \\
\hline Bilaterally successful lesions-baseline & $188(97.4 \%)$ & $5(2.6 \%)$ & $0(0.1 \%)$ & $0.159 \pm 0.152$ & $0.024-0.450$ & $97.0 \pm 9.4$ & $87.1-108.4$ \\
\hline Bilaterally successful lesions-postsurgery & $41(83.1 \%)$ & $3(6.9 \%)$ & $5(9.9 \%)$ & $0.088 \pm 0.078$ & $0.021-0.228$ & $32.0 \pm 21.8$ & $8.5-73.1$ \\
\hline
\end{tabular}

For vocalisations as well as for hand-following time, data gleaned from tickling days 4-6 were included in the baseline condition, and those from tickling days 7-10 in the post-surgical one. However, for the HAL-positivity index, data gleaned from all six available tickling sessions were included in the baseline as well as in the post-surgical condition. See Section 3 for an explanation of the rationale behind this approach.

those with unilaterally successful lesions $(0.484 v s .0 .344)$, and the strongest reduction - to $55 \%$ - was observed in rats with bilaterally successful lesions (0.159 vs. 0.088).

Data appertaining to the HAL-positivity index on individual experimental days are depicted in Fig. 6A-D. These graphs reveal that for animals in each of the four groups, there was at least one day after surgery on which they approached the experimenter's hand much less than on the last baseline day (tickling day 6). In all groups, including the controls, a pronounced reduction in the mean HAL-positivity index was observed between the last baseline and the first post-surgical day (tickling day 7).

The performance of individual rats in actively following the experimenter's hand during the "hand-chase" manipulation of the tickling sessions varied considerably, too. Similarly to the HAL-positivity index, the total hand-following time increased significantly during the six baseline days in the group of all 17 rats used in the present study (ANOVA, $F=2.52, p=0.036$ ). The same finding held true when the four rat groups were analysed separately, for the groups of the controls as well as animals with bilaterally successful lesions. For all 17 rats, the total hand-following time was larger at later than at earlier baseline days. As for the high-frequency vocalisations, the total following time on the last three baseline days (tickling days 4-6) was thus compared to that on the first four post-surgical days (tickling days 7-10).

In absolute values, the mean total hand-following time varied between 14.87 and $17.96 \mathrm{~s}$ for the four rat groups on the last three baseline days (data not shown). Only one rat in the control group did not follow the experimenter's hand at all during one of baseline days 4-6 (379_12 on baseline day 4). For each rat, the total hand-following time on baseline day $6(17.83 \pm 4.69 \mathrm{~s}$; range: $11.74-28.89 \mathrm{~s}$ ) was set to $100 \%$; the hand-following times on the last three baseline days, as well as on the first four days after surgery, were expressed as percentages of this value. The mean relative hand-following times varied between $86.7 \%$ and $125.9 \%$ for the four rat groups on the last three baseline days (Table 2). Overall, the animals in each of the four groups followed the experimenter's hand less well on the first four days after surgery than on the last baseline day (relative following times $<100 \%$ ). Moreover, in all four groups, the mean hand-following time on the first four days after surgery was lower than the mean following time on the last three baseline days. The most pronounced reduction in the mean relative following time was observed in the group of animals with bilaterally successful lesions. The value decreased from $97.0 \%$ before lesioning to $32.0 \%$ thereafter, which corresponds to a reduction to $33 \%$ of late baseline values. In the other three groups, the mean relative following time was reduced only to $58 \%$ (unilaterally successful lesions), 50\% (control-like lesions) and 76\% (controls) of the late baseline values.

Data appertaining to the relative hand-following times on individual experimental days are presented in Fig. 7A-D. These graphs reveal that in controls as well as in the animals with controllike lesions, the relative hand-following time, although somewhat reduced, remained relatively constant during the post-surgical days. In the group of rats with unilaterally successful lesions, the relative hand-following time decreased markedly between the last baseline and the first post-surgical day; during the subsequent five post-surgical days, the values were similar to those in the controls. Only in the group of animals with bilaterally successful lesions was the reduction in the relative hand-following time between the last baseline and the first post-surgical day protracted thereafter.

We conclude from these data that successful lesioning of PV-ir neurons in the parvafox nucleus is accompanied by a reduction in the rat's tendency to follow the experimenter's hand, which exceeded that accompanying the surgical manipulations that spared the resident population of PV-ir neurons.

Supplementary video 1 (electronic version only) depicts the behaviour of a suture control rat (382_12) and of a rat with a unilaterally successful lesion (383_12) on the second post-surgical day (tickling day 8) during two exemplary tickling manipulations ("neck tickle" and "push \& drill"), as well as during the following of and the approach towards the experimenter's hand during the "hand-chase" manipulation and the HAL-test, respectively.

\subsection{Regression analyses/curve estimations}

To tackle our main question, namely, whether successful lesioning of the parvafox nucleus leads to a reduction in the number of high-frequency calls, the total number of PV-ir cells was related to the level to which the total number of high-frequency calls was reduced during the first four post-surgical days (days 7-10) compared to the call levels that were attained during the last three baseline days (days 4-6) in each of the 17 rats. The curve that was found to best describe the relationship between these two parameters was a power function $(R=0.65, p=0.005 ; y=0.0004 x \hat{2} .16)$ (Fig. 8A).

We asked next whether the number of PV-ir cells correlated with surgery-associated changes in the other two parameters that were used to assess positive affective behaviour: the propensity to follow (hand-chase: following time) or approach (HAL-test: HAL-positivity index) the experimenter's hand. Also the relationship between the surgery-associated change in following time and the total number of PV-ir cells was best fitted by a power function $(R=0.59, p=0.012 ; y=1.47 x \hat{0} .65)$ (Fig. 8B). On the other hand, 
A

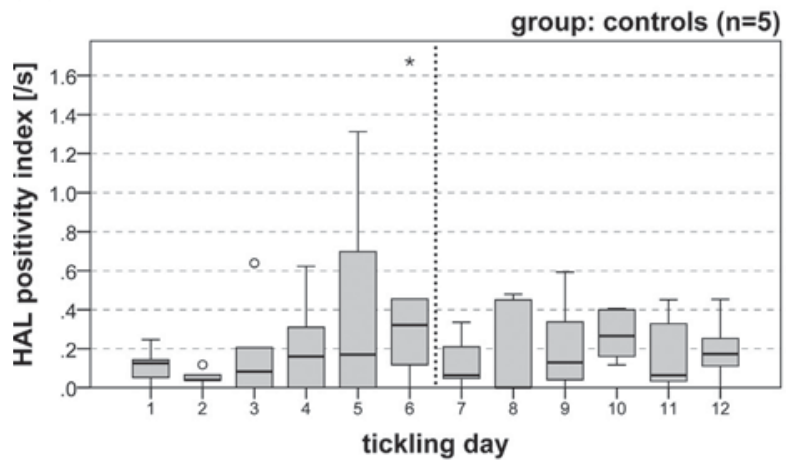

C

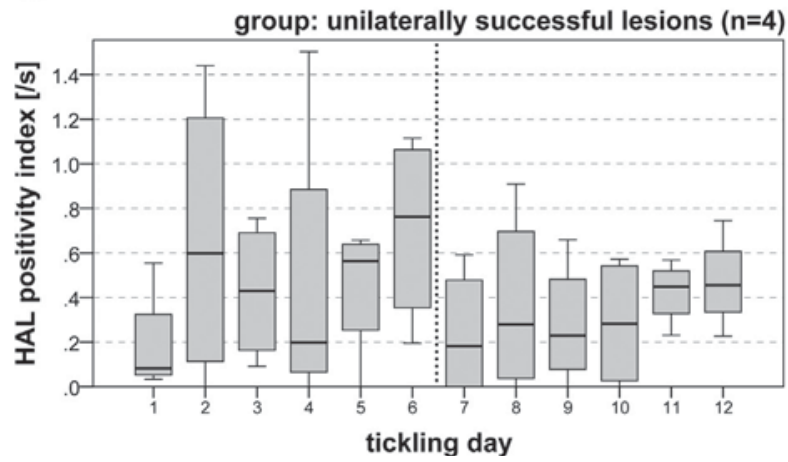

B

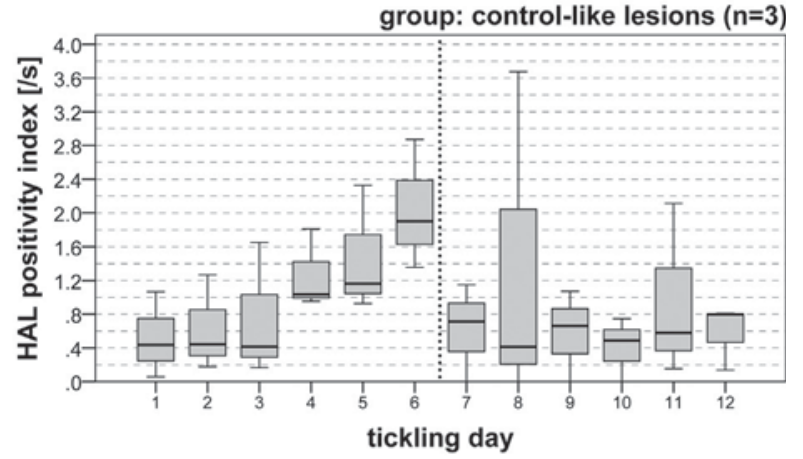

D

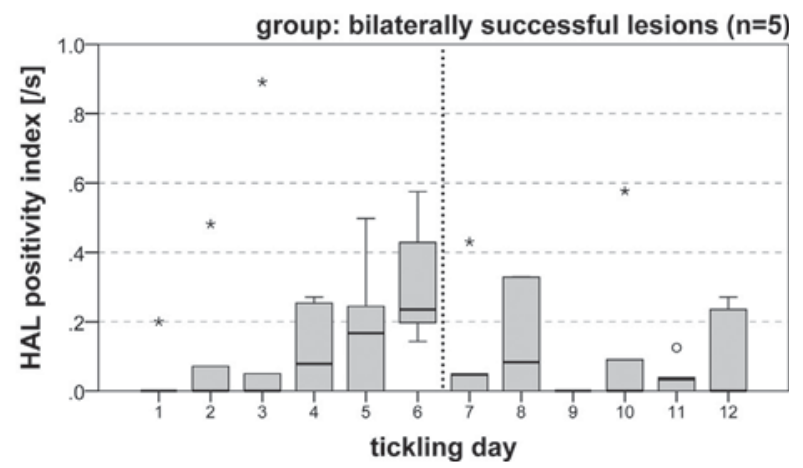

Fig. 6. The most profound reduction in the HAL-positivity index (HAL-test) was observed in rats with bilaterally successful lesions.

The HAL-positivity index for each rat in the four groups was derived from the results of the hand-approach latency (HAL) test conducted after each tickling session. The HAL-positivity index was derived by dividing the total number of hand approaches by the mean latency to touch it. In the control group, the mean HAL-positivity index on post-surgical days varied between $26 \%$ (day 7 ) and $53 \%$ (day 10) of the day- 6 baseline values (A), whereas in rats with bilaterally successful lesions, it varied between $0 \%$ (day 9 ) and $47 \%$ (day 8 ) of the day- 6 baseline values (D). Note that the ordinate scales span different ranges.

the relationship between the surgery-associated change in the HAL-positivity index and the total number of PV-ir cells was best described by a linear regression $(R=0.53, p=0.028 ; y=0.33 x+5.49)$ (Fig. 8C). Taken together, the absolute numbers of PV-ir cells counted in the 17 rats correlated with each of the three parameters used in the present study to quantify positive affect-related behaviour, whilst the characteristics of the relationships varied from parameter to parameter.

Further regression analyses were undertaken to probe the nature of the relationship between surgery-associated changes in the three different parameters used to assess positive affective behaviour. The relationship between the surgery-associated changes in the number of high-frequency calls and in the handfollowing time was again best fitted by a power function $(R=0.64$, $p=0.006 ; y=20.97 x 0 \hat{0} .21$ ) (Fig. 8D). The relationship between the surgery-associated changes in the number of high-frequency calls and in the HAL-positivity index was best described by a logarithmic function $(R=0.59, p=0.013 ; y=-19.63+28.10 \times \log [x])$ (Fig. 8E). Of all the correlations, the linear relationship between the surgery-associated changes in the hand-following time and in the HAL-positivity index was the closest $(R=0.76, p<0.001$; $y=2.27 x-35.97$ ) (Fig. 8F). In other words, rats in which the number of high-frequency vocalisations after surgery was reduced relative to baseline, also followed the experimenter's hand less well and approached it less than during the baseline sessions. The correlation between the two parameters that related to the experimenter's hand was stronger than that existing between either of these and the high-frequency vocalisations.

\section{Discussion}

With a view to ascertaining whether parvalbuminimmunoreactive (PV-ir) neurons in the parvafox nucleus play a role in the vocalisation and positive affective behaviour of rats, we adopted an approach that combined tickling with excitotoxic lesioning of the targeted lateral hypothalamic structure. Earlier studies on the effect of lesions on vocalisations and related emotional behaviours have been conducted mainly on primates or on mammalian species other than the rat [67]. We are aware of only one such study in rats, which demonstrated a reduction in frequency-modullated $50-\mathrm{kHz}$ calls after a destruction of the mesolimbic dopamine system [22].

In preliminary experiments, we attempted to lesion the parvafox nucleus using electrolytic lesions or a stereotactic injection of ibotenic acid. In the former case, the lesions were highly unspecific and implicated also the nerve-fibre tracks, whereas in the latter, the damage was very limited, with maximally $20-30 \%$ of the PV-ir cells being eliminated. In our hands, a cerebral injection of kainic acid proved to be the most efficacious and useful method of lesioning.

Of the four groups of rats that were established (controls, control-like lesions, unilaterally and bilaterally successful lesions), the one in which the animals had bilaterally successful lesions manifested the most profound reduction in the $50-\mathrm{kHz}$ call-numbers on the post-surgical days relative to the baseline levels (Figs. 4 and 5). In two of the animals with unilaterally successful lesions, considerable reductions in the number of $50-\mathrm{kHz}$ calls were likewise observed during the first few post-surgical days (Fig. S2). But in these two cases (380_12 and 383_12), the parameter rose again steeply during the very last two sessions, which could reflect a compensatory response of the neurons on the better preserved 
A

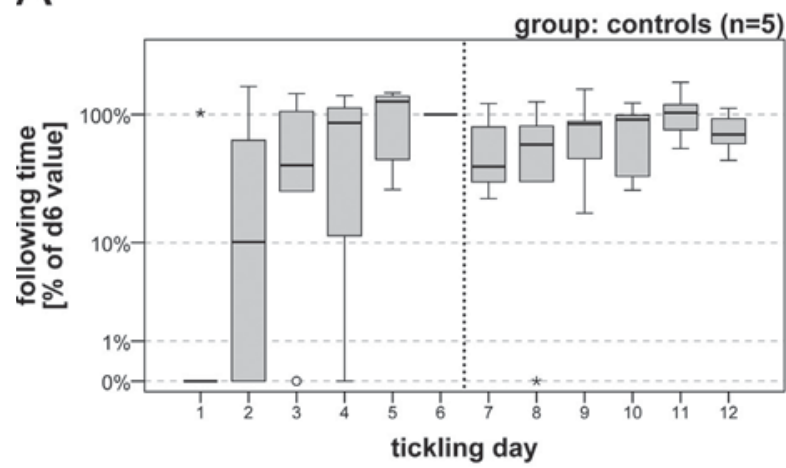

C

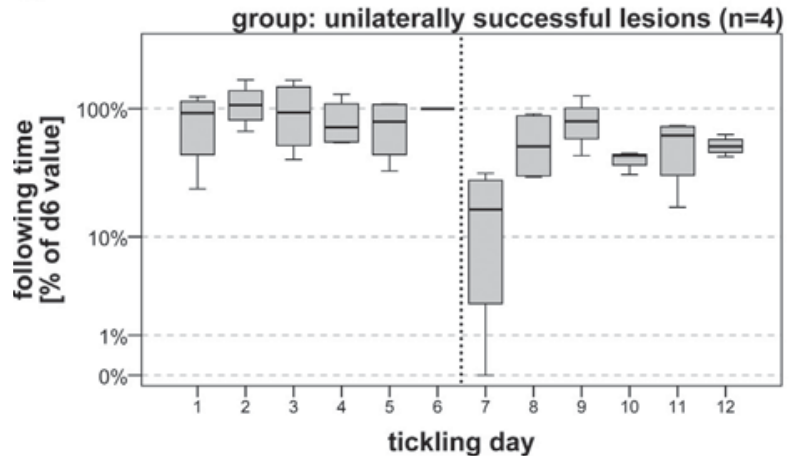

B

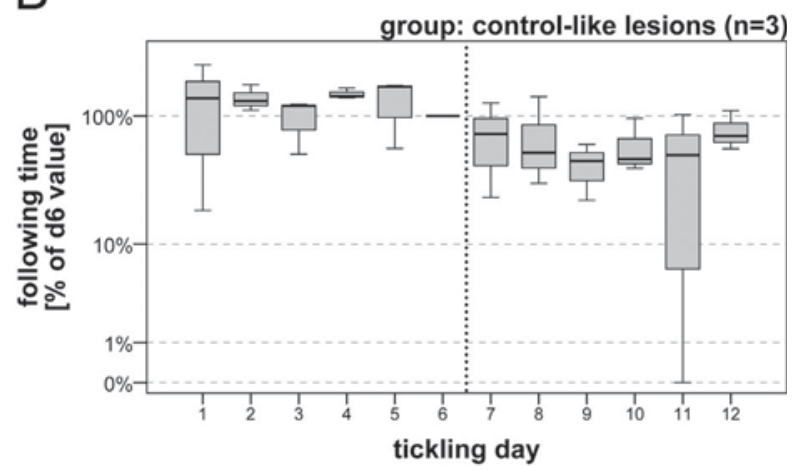

$\mathrm{D}$

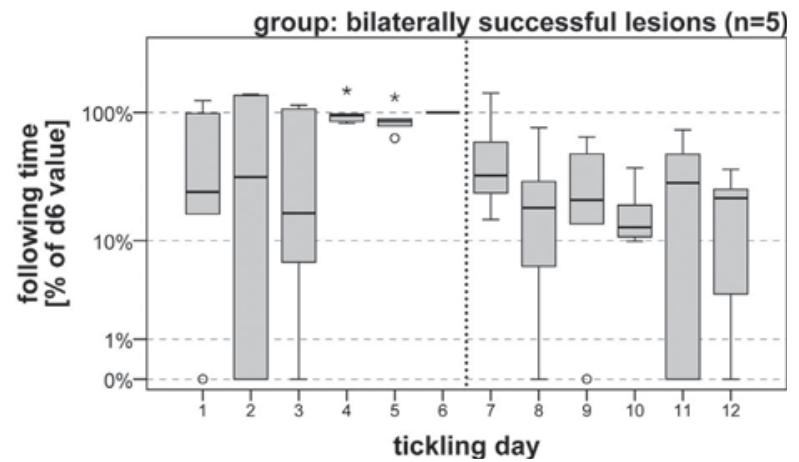

Fig. 7. The greatest and most persistent reduction in the hand-following time was observed in rats with bilaterally successful lesions.

Relative hand-following times of rats in the four groups during the "hand-chase" manipulation of individual tickling sessions, expressed as a percentage of the following time for each rat during the last baseline session. In the control group, the mean following time on post-surgical days varied between 59\% (day 7) and 106\% (day 11) of the day-6 baseline values (A), whereas in rats with bilaterally successful lesions it varied between $18 \%$ (day 12 ) and $54 \%$ (day 7 ) of the day-6 baseline values (D). Note that the ordinate scales are logarithmic.

side. In only one of the 17 rats were control-like numbers of PV-ir cells observed in conjunction with a complete abolishment of the $50-\mathrm{kHz}$ USVs after surgery (381_12). And it was precisely in this rat that an unusual pattern of microglial staining was observed: it was the only animal - apart from the two with bilaterally successful lesions (Fig. 3B) - in which activated microglia were located within the region of the parvafox nucleus itself. In less successful lesions, they were usually encountered at some distance therefrom. One explanation for the finding might be that in this rat, kainic acid led to death of not the PV core neurons, but potentially of the Foxb1-expressing neurons surrounding them. One limitation of the present study was that there was no possibility to assess the effect of the excitotoxin lesion on the Foxb1 sub-population. Using a strain of mice that expresses Cre recombinase under the control of the Foxb1-promoter [68], it has been possible to characterise in detail the topography and the morphological features of the Foxb1expressing cells in the parvafox nucleus [4]. To date, all attempts to map Foxb1-immunoreactivity in wild-type mice or rats using specific antibodies have failed.

Notwithstanding this limitation, when the raw data appertaining to the individual 17 rats were considered as a whole, irrespective of the group affiliations, a close correlation was found between the total absolute number of PV-ir cells counted on both sides and the surgery-associated change in the number of $50-\mathrm{kHz}$ calls. This correlation was best described by a specific power function (Fig. 8A), which suggests that the elimination of, for example, the first $10 \%$ of the PV-ir neurons has a much greater impact on the reduction in the $50-\mathrm{kHz}$ call number than does the elimination of the last $10 \%$.

Not only the surgery-associated reduction in the number of $50-\mathrm{kHz}$ calls that were emitted during the tickling sessions, but also the surgery-associated reduction in the other two parameters assessed, namely, HAL-positivity index (Fig. 6) and the total hand-following time during the "hand-chase" tickling manipulation (Fig. 7), were most pronounced in the five rats with bilaterally successful lesions. This finding supports our hypothesis that the reduction in the number of $50-\mathrm{kHz}$ USVs observed after successful lesioning of the parvafox nucleus is attributable to a change in emotional rather than in motor processing. Averaged across groups, values for both HAL-positivity index and total hand-following time were somewhat reduced immediately after surgery in all other three groups as well. This finding suggests that either the anaesthesia or the surgical manipulations themselves had a negative impact on the tendency of the rats to approach and follow the experimenter's hand, or that the animals lost interest in or excitement about these tests when they were too often repeated (no research group has before repeated the HAL-test more than four times, and the only effect of repetition reported in the literature is a decrease in approach latency $[53,69])$. Since in the present study, the group means usually continued to increase even between baseline days 4 and 6, an unspecific effect of the surgical manipulations would appear to be the more likely explanation. However, also for the two parameters used to assess positive affect-related behaviour, close correlations were found between the total absolute number of PVir cells counted on both sides and the surgery- associated change in either of these (Fig. 8B \& C). The fact that additional positive correlations were found between pairs of the three parameters measured (surgery-associated change in the number of $50-\mathrm{kHz}$ USVs, in the HAL-positivity index and in the hand-following time; Fig. 8D-F), further demonstrates that lesioning affected not only the vocalisations but rather the expression of positive emotions in response 
A

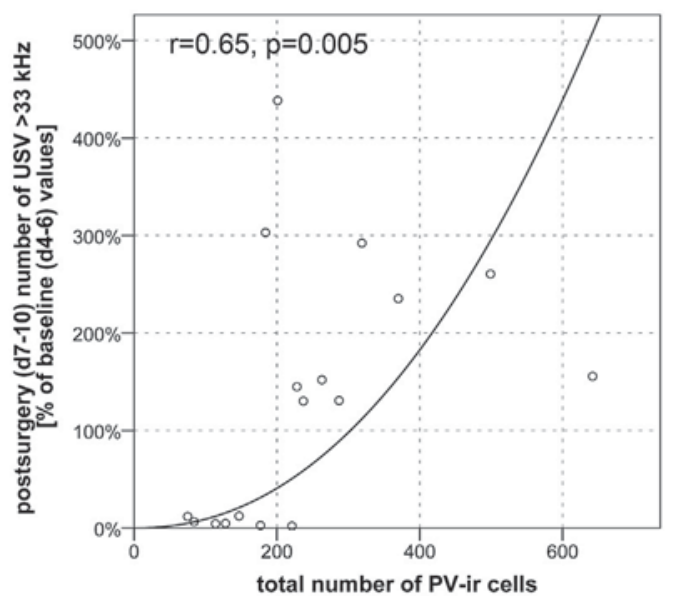

C

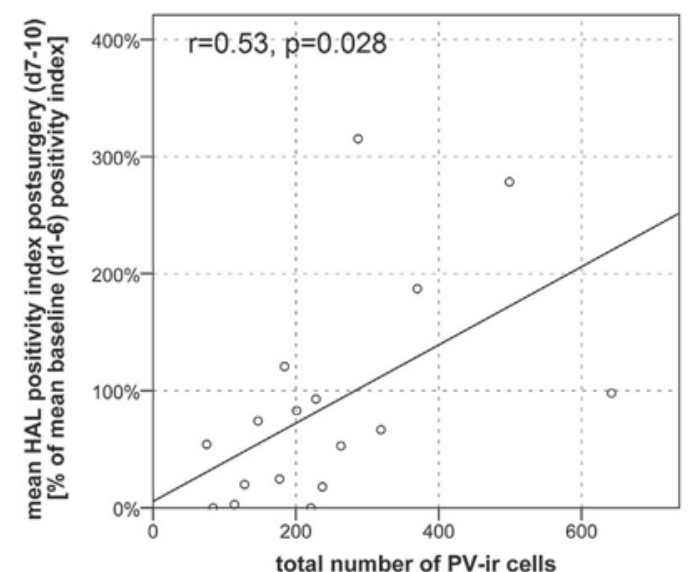

E

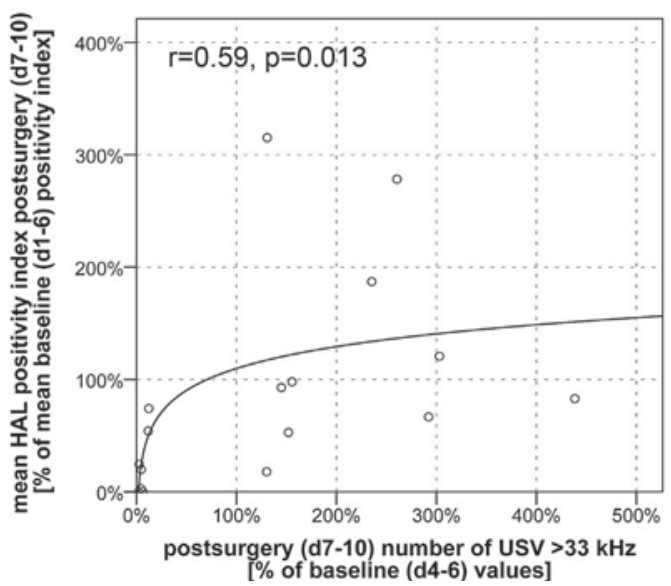

B
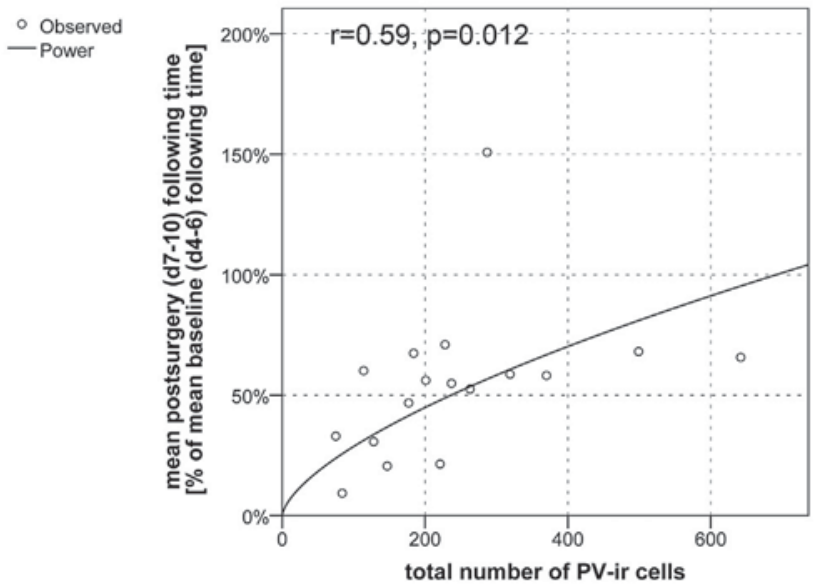

$\circ$ Observed

- Power

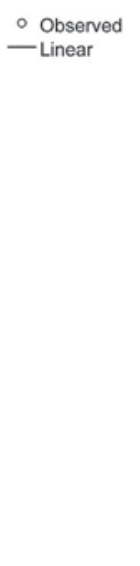

F

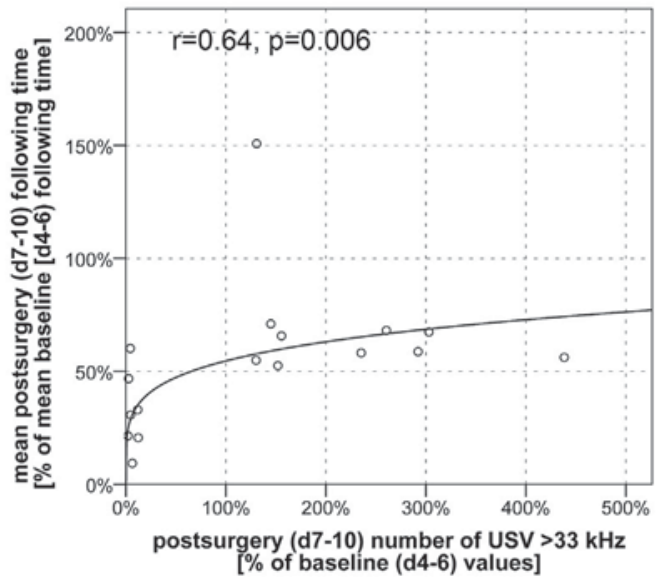

- Observed - Power
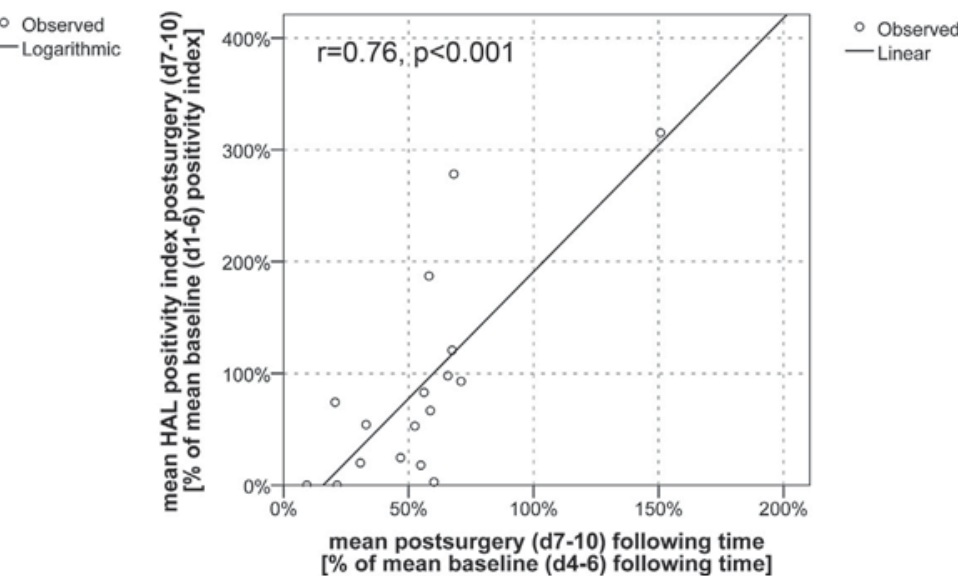

Fig. 8. The number of PV-ir cells correlates with surgery-associated changes in all parameters that were used to assess positive affect-related behaviour.

Regression analysis was conducted to probe the nature of the relationship that existed between the various parameters used in the present study to assess positive affect related behaviour, and between each of these and the number of PV-ir cells. In each graph, the 17 circles represent data appertaining to the 17 individual rats; the continuous line is a trace of the function (amongst the options: linear/logarithmic/power/logistic/exponential) that best fitted the observed points. The relationship between the number of PV-ir cells and the surgery-associated change in high-frequency vocalisations was best described by a power function (A). The relationship between the number of PV-ir cells and the surgery-associated change in the hand-following time was likewise best described by a power function (B). The relationship between the number of PV-ir cells and the surgery-associated change in the HAL-positivity index (HAL-test) was best described by a linear function (C). (D-F): A correlation was found between each of the three parameters used to assess positive affect-related behaviour. The relationship between the surgery-associated change in high-frequency vocalisations and in hand-following time was again best described by a power function (D). The relationship between the surgery-associated change in high-frequency vocalisations and in HAL-positivity index was best described by a logarithmic function (E). Of all the correlations, the linear relationship that existed between the surgery-associated change in hand-following time and in HAL-positivity index was the closest (F). See Section 3 for details of the experimental days included in the calculations for the various parameters. 
to the tickling manipulation and the experimenter's hand in its entirety.

We suggest that neurons in the lateral hypothalamus or rather, more specifically, the PV-expressing sub-population of the parvafox nucleus, are involved in the production of $50-\mathrm{kHz}$ USVs. In the context of lateral hypothalamic manipulations, it is of particular importance to distinguish between effects mediated by local neurons and those mediated by by-passing fibres, owing to the presence of the medial forebrain bundle (MFB), which carries fibres of the mesolimbic dopamine system. The lateral hypothalamus as well as the prefrontal cortex - are counted amongst the brain areas that support the most vigorous self-stimulation behaviour in rats; upon electrical stimulation, they induce $50-\mathrm{kHz}$ calling [22]. In anticipation of a rewarding electrical brain stimulation of the LHA, rats augment the emission of $50-\mathrm{kHz}$ USVs [70]. Obviously, this response is (as least partially) attributable to a stimulation of fibres in the mesolimbic dopamine system running within the MFB, and which is known to increase $50-\mathrm{kHz}$ call-rates $[22,70]$. However, there is evidence for reward mechanisms originating in the LHA itself, and intracranial self-stimulation in this area was found to be at least partially sustained by an activation not of the passing dopaminergic fibres in the MFB [71], but of local neurons $[72,73]$. Moreover, the injection of an excitotoxin such as kainic acid into the brain is classically believed to destroy local cell bodies not by-passing fibres. An injection of one of two other excitotoxins, namely ibotenic acid and NMDA, into the lateral hypothalamus has been shown to produce a zone of neuronal killing, that exceeds in extent that of demyelination [74]. The author of the study reasoned that kainic acid might exert a less severe demyelinating effect than either ibotenic acid or NMDA. In other studies, an injection of either kainic acid [75] or ibotenic acid [76] into the LHA induced the degeneration of neuronal bodies but no significant destruction of by-passing fibres (of the MFB).

Kainic acid acts as an agonist on glutamate receptors of both the kainate and the AMPA subtypes [77]. Although kainate receptors along axons are possible, these are usually located close to active zones [78]. Kainic acid-induced neuronal death in the rat hippocampus is accompanied by an increase in the proliferative rates of astrocytes and microglia [79], but rather not by a complete destruction of by-passing axons. Since the volumes of kainic acid injected in the present study did not suffice even to eliminate in entirety the small PV sub-population of parvafox neurons, it is reasonable to assume that the excitotoxin did not interfere with the function of the mesolimbic dopamine system by directly destroying by-passing fibres.

Any local neuron in the region of the parvafox nucleus could of course have been affected by the lesions and have contributed to the observed post-surgical phenotype. However, the correlations found between the number of PV-ir parvafox cells and the surgery-associated change in all three of the investigated parameters (number of 50-kHz USVs, hand-following time, HAL-positivity index) suggest a significant contribution of this sub-population.

Broadening our view beyond the rat species, evidence for a role of PV-expressing neurons in the context of vocalisation already exists. PV-expression in the songbird is confined to specific neuronal populations that are especially involved in song-learning [80-82]. This finding suggests that PV fulfills a specific function in these neurons that is potentially related to their morphological plasticity in the context of vocal learning (see also [83]); or, alternatively, to their protection against $\mathrm{Ca}^{2+}$-toxicity from the highly active neurons that control some of the fastest muscles in the body [84]. Furthermore, in avian as well as in primate species, PV is differentially up-regulated in the vocal motor neurons of vocal learners (learned songs or spoken language) compared to nonlearners [85]. And in PV-knockout mice, deficits in social interaction as well as in communication are observed [86]. Hence, the neuronal properties that are mediated by the $\mathrm{Ca}^{2+}$-buffer $\mathrm{PV}$ might be particularly required by neurons involved in the production of vocalisations.

The precise role played by the parvafox nucleus in the production of vocalisations, as well as in the context of positive emotions, remains elusive. Bearing in mind the complex and wide-ranging connections of the two sub-populations of neurons that comprise the parvafox nucleus, namely, the PV-ir core cells and the Foxb1expressing ones of the shell surrounding this core, as well as the partially opposing functions of the brain centres targeted by them, we hypothesise that the functions are not confined to the production of vocalisations, but embrace also on the generation or display of specific emotional states, which possibly includes an interaction with various manifestations of the autonomic nervous system $[87,88]$ and perhaps also with nociception pathways [89-91].

In summary, the present study affords evidence that the parvalbumin expressing sub-population of neurons in the hypothalamic parvafox nucleus plays a role in the expression of positive emotions in rats as manifested by the emission of ultrasonic vocalisations and animal approach behaviours.

\section{Acknowledgments}

The authors are indebted to Daniele Milani and Ines Mottas for performing the tickling experiments, and to Laurence Clément, Christiane Marti and Simone Eichenberger for their technical assistance. The present work was funded under grant 31003A-144036 of the Swiss National Foundation.

\section{Appendix A. Supplementary data}

Supplementary data associated with this article can be found, in the online version, at http://dx.doi.org/10.1016/j.bbr.2015.11.004.

\section{References}

[1] H.R. Berthoud, H. Munzberg, The lateral hypothalamus as integrator of metabolic and environmental needs: from electrical self-stimulation to opto-genetics, Physiol. Behav. 104 (2011) 29-39.

[2] C.B. Saper, Hypothalamus The Human Nervous System, Academic Press, 2012, pp. $548-583$.

[3] L. de Leces, T.S. Kilduff, C. Peyron, X. Gao, P.E. Foye, P.E. Danielson, et al., The hypocretins: hypothalamus-specific peptides with neuroexcitatory activity, Proc. Natl. Acad. Sci. U. S. A. 95 (1998) 322-327.

[4] A. Bilella, G. Alvarez-Bolado, M.R. Celio, Coaxiality of Foxb1- and parvalbumin-expressing neurons in the lateral hypothalamic PV1-nucleus, Neurosci. Lett. 566 (30 (April)) (2014) 111-114.

[5] M.R. Celio, Calbindin D-28k and parvalbumin in the rat nervous system, Neuroscience 35 (1990) 375-475.

[6] Z. Meszar, F. Girard, C.B. Saper, M.R. Celio, The lateral hypothalamic parvalbumin-immunoreactive (PV1) nucleus in rodents, J. Comp. Neurol. 520 (2012) 798-815.

[7] G. Alvarez-Bolado, M.R. Celio, The ventrolateral hypothalamic area and the parvafox nucleus: role in the expression of (positive) emotions? J. Comp. Neurol. (2015) [Epub ahead of print].

[8] M.R. Celio, A. Babalian, Q.H. Ha, S. Eichenberger, L. Clement, C. Marti, et al., Efferent connections of the parvalbumin-positive (PV1) nucleus in the lateral hypothalamus of rodents, J. Comp. Neurol. 521 (2013) 3133-3153.

[9] A. Bilella, G. Alvarez-Bolado, M.R. Celio, The Foxb 1-expressing neurons of the ventrolateral hypothalamic Parvafox nucleus project to regions involved in the defense reaction, J. Comp. Neurol. (2015).

[10] F. Girard, Z. Meszar, C. Marti, F.P. Davis, M. Celio, Gene expression analysis in the parvalbumin-immunoreactive PV1 nucleus of the mouse lateral hypothalamus, Eur. J. Neurosci. 34 (2011) 1934-1943.

[11] M.R. Celio, Parvalbumin in most gamma-aminobutyric acid-containing neurons of the rat cerebral cortex, Science 231 (1986) 995-997.

[12] B. Wild, F.A. Rodden, W. Grodd, W. Ruch, Neural correlates of laughter and humour, Brain 126 (2003) 2121-2138.

[13] S. Striano, L. Santulli, M. Ianniciello, M. Ferretti, P. Romanelli, P. Striano, The gelastic seizures-hypothalamic hamartoma syndrome: facts, hypotheses, and perspectives, Epilepsy Behav. 24 (2012) 7-13.

[14] A.T. Gerig, M.R. Celio, The human lateral tuberal nucleus: Immunohistochemical characterization and analogy to the rodent PV1-nucleus, Brain Res. 1139 (2007) 110-116. 
[15] H. Braak, E. Braak, Pick's disease: cytoskeletal changes in the hypothalamic lateral tuberal nucleus, Brain Res. 802 (1998) 119-124.

[16] X.W. Fu, S.M. Brudzynski, High-frequency ultrasonic vocalization induced by intracerebral glutamate in rats, Pharmacol. Biochem. Behav. 49 (1994) 835-841.

[17] I. Altafullah, C. Shipley, J.S. Buchwald, Voiced calls evoked by hypothalamic stimulation in the cat, Exp. Brain Res. 71 (1988) 21-32.

[18] U. Jürgens, Neurochemical study of PAG control of vocal behavior, in: A. Depaulis, R. Bandler (Eds.), The Midbrain Periaqueductal Gray Matter, Springer, US, 1991, pp. 11-21.

[19] E. Wattendorf, B. Westermann, K. Fiedler, E. Kaza, M. Lotze, M.R. Celio, Exploration of the neural correlates of ticklish laughter by functional magnetic resonance imaging, Cereb. Cortex 23 (2013) 1280-1289.

[20] H. Arita, I. Kita, M. Sakamoto, Two distinct descending inputs to the cricothyroid motoneuron in the medulla originating from the amygdala and the lateral hypothalamic area, Adv. Exp. Med. Biol. 393 (1995) 53-58.

[21] H. Tatsuta, H. Arita, Nonadrenergic relaxation of the cat cervical trachea evoked by stimulation in the lateral hypothalamic area, Neurosci. Res. 26 (1996) 315-322

[22] J. Burgdorf, P.L. Wood, R.A. Kroes, J.R. Moskal, J. Panksepp, Neurobiology of 50-kHz ultrasonic vocalizations in rats: electrode mapping, lesion, and pharmacology studies, Behav. Brain Res. 182 (2007) 274-283.

[23] H.H. Subramanian, G. Holstege, The nucleus retroambiguus control of respiration, J. Neurosci. 29 (2009) 3824-3832.

[24] E.T. Rolls, Information processing in the taste system of primates, J. Exp. Biol. 146 (1989) 141-164

[25] E.T. Rolls, The orbitofrontal cortex and reward, Cereb. Cortex 10 (2000) 284-294.

[26] T.V. Sewards, M.A. Sewards, Representations of motivational drives in mesia cortex, medial thalamus, hypothalamus and midbrain, Brain Res. Bull. 61 (2003) 25-49

[27] R. Bandler, A. Depaulis, Midbrain periaqueductal gray control of defensive behavior in the cat and the rat, in: A. Depaulis, R. Bandler (Eds.), The Midbrain Periaqueductal Gray Matter, Springer, US, 1991, pp. 175-198.

[28] R. Bandler, M.T. Shipley, Columnar organization in the midbrain periaqueductal gray: modules for emotional expression? Trends Neurosci. 17 (1994) 379-389.

[29] R. Bandler, K.A. Keay, N. Floyd, J. Price, Central circuits mediating patterned autonomic activity during active vs. passive emotional coping, Brain Res. Bull. 53 (2000) 95-104

[30] U. Jurgens, The neural control of vocalization in mammals: a review, J. Voice 23 (2009) 1-10.

[31] J.W. Brown, Physiology and phylogenesis of emotional expression, Brain Res. 5 (1967) $1-14$

[32] E.S. Luschei, L.O. Ramig, E.M. Finnegan, K.K. Baker, M.E. Smith, Patterns of laryngeal electromyography and the activity of the respiratory system during spontaneous laughter, J. Neurophysiol. 96 (2006) 442-450.

[33] E.C. Lauterbach, J.L. Cummings, P.S. Kuppuswamy, Toward a more precise, clinically-informed pathophysiology of pathological laughing and crying, Neurosci. Biobehav. Rev. 37 (2013) 1893-1916.

[34] U. Jurgens, The role of the periaqueductal grey in vocal behaviour, Behav Brain Res. 62 (1994) 107-117.

[35] R.J. Waldbillig, Attack eating, drinking, and gnawing elicited by electrical stimulation of rat mesencephalon and pons, J. Comp. Physiol. Psychol. 89 (1975) 200-212.

[36] S. Kyuhou, H. Gemba, Two vocalization-related subregions in the midbrain periaqueductal gray of the guinea pig, Neuroreport 9 (1998) 1607-1610.

[37] C.L. Lu, U. Jurgens, Effects of chemical stimulation in the periaqueductal gray on vocalization in the squirrel monkey, Brain Res. Bull. 32 (1993) 143-151.

[38] R. Bandler, P. Carrive, Integrated defence reaction elicited by excitatory amino acid microinjection in the midbrain periaqueductal grey region of the unrestrained cat, Brain Res. 439 (1988) 95-106.

[39] T.A. Lovick, Interactions between descending pathways from the dorsal and ventrolateral periaqueductal gray matter in the rat, in: A. Depaulis, R. Bandler (Eds.), The Midbrain Periaqueductal Gray Matter, Springer, US, 1991, pp. $101-120$.

[40] M. Wohr, R.K. Schwarting Affective communication in rodents: ultrasonic vocalizations as a tool for research on emotion and motivation, Cell. Tissue Res. 354 (2013) 81-97.

[41] J. Burgdorf, R.A. Kroes, J.R. Moskal, J.G. Pfaus, S.M. Brudzynski, J. Panksepp, Ultrasonic vocalizations of rats (Rattus norvegicus) during mating, play, and aggression: behavioral concomitants, relationship to reward, and self-administration of playback, J. Comp. Psychol. 122 (2008) 357-367.

[42] T.K. McIntosh, R.J. Barfield, D. Thomas, Electrophysiological and ultrasonic correlates of reproductive behavior in the male rat, Behav. Neurosci. 98 (1984) 1100-1103.

[43] J.A. Matochik, N.R. White, R.J. Barfield, Variations in scent marking and ultrasonic vocalizations by Long-Evans rats across the estrous cycle, Physiol. Behav. 51 (1992) 783-786

[44] M. Willadsen, D. Seffer, R.K. Schwarting, M. Wohr, Rodent ultrasonic communication: male prosocial $50-\mathrm{kHz}$ ultrasonic vocalizations elicit social approach behavior in female rats (Rattus norvegicus), J. Comp. Psychol. 128 (2014) 56-64.

[45] N.C. Heyse, J.C. Brenes, R.K. Schwarting, Exercise reward induces appetitive 50-kHz calls in rats, Physiol. Behav. 147 (2015) 131-140.
[46] B. Knutson, J. Burgdorf, J. Panksepp, High-frequency ultrasonic vocalizations index conditioned pharmacological reward in rats, Physiol. Behav. 66 (1999) 639-643.

[47] N. Simola, S. Fenu, G. Costa, A. Pinna, A. Plumitallo, M. Morelli, Pharmacological characterization of $50-\mathrm{kHz}$ ultrasonic vocalizations in rats: comparison of the effects of different psychoactive drugs and relevance in drug-induced reward, Neuropharmacology 63 (2012) 224-234.

[48] J. Burgdorf, J. Panksepp, J.R. Moskal, Frequency-modulated 50kHz ultrasonic vocalizations: a tool for uncovering the molecular substrates of positive affect, Neurosci. Biobehav. Rev. 35 (2011) 1831-1836.

[49] B. Knutson, J. Burgdorf, J. Panksepp, Ultrasonic vocalizations as indices of affective states in rats, Psychol. Bull. 128 (2002) 961-977.

[50] S.M. Brudzynski, Ethotransmission communication of emotional states through ultrasonic vocalization in rats, Curr. Opin. Neurobiol. 23 (2013) 310-317.

[51] J. Panksepp, J. Burgdorf, 50-kHz chirping (laughter?) in response to conditioned and unconditioned tickle-induced reward in rats: effects of social housing and genetic variables, Behav. Brain Res. 115 (2000) 25-38.

[52] J. Panksepp, Neuroevolutionary sources of laughter and social joy: modeling primal human laughter in laboratory rats, Behav. Brain Res. 182 (2007) 231-244.

[53] J. Burgdorf, J. Panksepp, Tickling induces reward in adolescent rats, Physiol. Behav. 72 (2001) 167-173.

[54] J. Panksepp, J. Burgdorf, Laughing rats and the evolutionary antecedents of human joy? Physiol. Behav. 79 (2003) 533-547.

[55] N.R. White, R.J. Barfield, Role of the ultrasonic vocalization of the female rat (Rattus norvegicus) in sexual behavior, J. Comp. Psychol. 101 (1987) 73-81.

[56] N.R. White, R.J. Barfield, Effects of male pre-ejaculatory vocalizations on female receptive behavior in the rat (Rattus norvegicus), J. Comp. Psychol. 104 (1990) 140-146.

[57] M. Wohr, R.K. Schwarting, Ultrasonic communication in rats: can playback of 50-kHz calls induce approach behavior? PLoS One 2 (2007) e1365.

[58] D. Seffer, R.K. Schwarting, M. Wohr, Pro-social ultrasonic communication in rats: insights from playback studies, J. Neurosci. Methods 234 (2014) 73-81.

[59] R.J. Blanchard, D.C. Blanchard, R. Agullana, S.M. Weiss, Twenty-two kHz alarm cries to presentation of a predator, by laboratory rats living in visible burrow systems, Physiol. Behav. 50 (1991) 967-972.

[60] S.M. Brudzynski, Principles of rat communication: quantitative parameters of ultrasonic calls in rats, Behav. Genet. 35 (2005) 85-92.

[61] C.V. Portfors, Types and functions of ultrasonic vocalizations in laboratory rats and mice, J. Am. Assoc. Lab. Anim. Sci. 46 (2007) 28-34.

[62] A. Depaulis, K.A. Keay, R. Bandler, Longitudinal neuronal organization of defensive reactions in the midbrain periaqueductal gray region of the rat, Exp. Brain Res. 90 (1992) 307-318.

[63] E.J. Kim, O. Horovitz, B.A. Pellman, L.M. Tan, Q. Li, G. Richter-Levin, et al., Dorsal periaqueductal gray-amygdala pathway conveys both innate and learned fear responses in rats, Proc. Natl. Acad. Sci. U. S. A. 110 (2013) 14795-14800.

[64] R.K. Schwarting, N. Jegan, M. Wohr, Situational factors, conditions and individual variables which can determine ultrasonic vocalizations in male adult Wistar rats, Behav. Brain Res. 182 (2007) 208-222.

[65] D. Ito, Y. Imai, K. Ohsawa, K. Nakajima, Y. Fukuuchi, S. Kohsaka, Microglia-specific localisation of a novel calcium binding protein, Iba1, Brain Res. Mol. Brain Res. 57 (1998) 1-9.

[66] J. Gehrmann, S.W. Schoen, G.W. Kreutzberg, Lesion of the rat entorhinal cortex leads to a rapid microglial reaction in the dentate gyrus. A light and electron microscopical study, Acta Neuropathol. 82 (1991) 442-455.

[67] J. Panksepp, Affective Neuroscience: The Foundations of Human and Animal Emotions, Oxford University Press, 1998

[68] T. Zhao, N. Szabo, J. Ma, L. Luo, X. Zhou, G. Alvarez-Bolado, Genetic mapping of Foxb1-cell lineage shows migration from caudal diencephalon to telencephalon and lateral hypothalamus, Eur. J. Neurosci. 28 (2008) 1941-1955.

[69] J. Panksepp, J. Burgdorf, Laughing Rats Playful Tickling Arouses High-Frequency Ultrasonic Chirping in Young Rodents. Toward a Science of Consciousness III, A Bradford Book, 1999, pp. 231-244.

[70] J. Burgdorf, B. Knutson, J. Panksepp, Anticipation of rewarding electrical brain stimulation evokes ultrasonic vocalization in rats, Behav. Neurosci. 114 (2000) 320-327.

[71] C. Bielajew, P. Shizgal, Behaviorally derived measures of conduction velocity in the substrate for rewarding medial forebrain bundle stimulation, Brain Res. 237 (1982) 107-119.

[72] L. Velley, The role of intrinsic neurons in lateral hypothalamic self-stimulation, Behav. Brain Res. 22 (1986) 141-152.

[73] K. Nakamura, T. Ono, Lateral hypothalamus neuron involvement in integration of natural and artificial rewards and cue signals, J. Neurophysiol. 55 (1986) 163-181.

[74] J.R. Stellar, F.S. Hall, M. Waraczynski, The effects of excitotoxin lesions of the lateral hypothalamus on self-stimulation reward, Brain Res. 541 (1991) 29-40.

[75] S.P. Grossman, D. Dacey, A.E. Halaris, T. Collier, A. Routtenberg, Aphagia and adipsia after preferential destruction of nerve cell bodies in hypothalamus, Science 202 (1978) 537-539.

[76] S. Hansen, C. Kohler, M. Goldstein, H.V. Steinbusch, Effects of ibotenic acid-induced neuronal degeneration in the medial preoptic area and the lateral hypothalamic area on sexual behavior in the male rat, Brain Res. 239 (1982) 213-232. 
[77] J.H. Weiss, S.L. Sensi, Ca2+-Zn2+ permeable AMPA or kainate receptors: possible key factors in selective neurodegeneration, Trends Neurosci. 23 2000) 365-371

[78] F. Jaskolski, F. Coussen, C. Mulle, Subcellular localization and trafficking of kainate receptors, Trends Pharmacol. Sci. 26 (2005) 20-26.

[79] Q. Wang, S. Yu, A. Simonyi, G.Y. Sun, A.Y. Sun, Kainic acid-mediated excitotoxicity as a model for neurodegeneration, Mol. Neurobiol. 31 (2005) $3-16$.

[80] F. Nottebohm, T.M. Stokes, C.M. Leonard, Central control of song in the canary, Serinus canarius, J. Comp. Neurol. 165 (1976) 457-486.

[81] W. Zuschratter, H. Scheich, C.W. Heizmann, Ultrastructural localization of the calcium-binding protein parvalbumin in neurons of the song system of the zebra finch, Poephila guttata, Cell Tissue Res. 241 (1985) 77-83.

[82] K. Braun, H. Scheich, C.W. Heizmann, W. Hunziker, Parvalbumin and calbindin-D28K immunoreactivity as developmental markers of auditory and vocal motor nuclei of the zebra finch, Neuroscience 40 (1991) 853-869.

[83] T.S. Balmer, V.M. Carels, J.L. Frisch, T.A. Nick, Modulation of perineuronal nets and parvalbumin with developmental song learning, J. Neurosci. 29 (2009) $12878-12885$

[84] A.R. Pfenning, E. Hara, O. Whitney, M.V. Rivas, R. Wang, P.L. Roulhac, et al., Convergent transcriptional specializations in the brains of humans and song-learning birds, Science 346 (2014) 1256846.
[85] E. Hara, M.V. Rivas, J.M. Ward, K. Okanoya, E.D. Jarvis, Convergent differential regulation of parvalbumin in the brains of vocal learners, PLoS One 7 (2012) e29457.

[86] M. Wohr, D. Orduz, P. Gregory, H. Moreno, U. Khan, K.J. Vorckel, et al., Lack of parvalbumin in mice leads to behavioral deficits relevant to all human autism core symptoms and related neural morphofunctional abnormalities, Transl. Psychiatry 5 (2015) e525.

[87] F.M. Semenenko, B.M. Lumb, Excitatory projections from the anterior hypothalamus to periaqueductal gray neurons that project to the medulla: a functional anatomical study, Neuroscience 94 (1999) 163-174.

[88] R.A. Dampney, The hypothalamus and autonomic regulation: an overview, in: Central Regulation of Autonomic Functions, Oxford University Press, New York, 2011, pp. 47-61.

[89] M.M. Behbehani, M.R. Park, M.E. Clement, Interactions between the lateral hypothalamus and the periaqueductal gray, J. Neurosci. 8 (1988) 2780-2787.

[90] A.C. Franco, W.A. Prado, Antinociceptive effects of stimulation of discrete sites in the rat hypothalamus: evidence for the participation of the lateral hypothalamus area in descending pain suppression mechanisms, Braz. J. Med. Biol. Res. 29 (1996) 1531-1541.

[91] N. Dafny, W.Q. Dong, C. Prieto-Gomez, C. Reyes-Vazquez, J. Stanford, J.T. Qiao, Lateral hypothalamus: site involved in pain modulation, Neuroscience 70 (1996) 449-460 